\title{
ARTICLE
}

\section{Nanoscale All-Oxide-Heterostructured Bio-inspired Optoresponsive Nociceptor}

Cite as

Nano-Micro Lett.

(2020) 12:83

Received: 15 January 2020

Accepted: 2 March 2020

Published online: 1 April 2020

(C) The Author(s) 2020

\author{
Mohammad Karbalaei Akbari ${ }^{1,2} \bowtie$, Jie $\mathrm{Hu}^{3}$, Francis Verpoort ${ }^{4}$, Hongliang $\mathrm{Lu}^{5}$, \\ Serge Zhuiykov ${ }^{1,2} \bowtie$ \\ $\square$ Mohammad Karbalaei Akbari, Mohammad.akbari@ugent.be; Serge Zhuiykov, Serge.Zhuiykov@ugent.be \\ 1 Centre for Environmental and Energy Research, Ghent University Global Campus, Incheon, South Korea \\ 2 Department of Green Chemistry and Technology, Faculty of Bioscience Engineering, Ghent University, \\ 9000 Ghent, Belgium \\ 3 College of Information Engineering, Taiyuan University of Technology, Taiyuan 030024, Shanxi, \\ People's Republic of China \\ 4 Laboratory of Organometallics, Catalysis and Ordered Materials, State Key Laboratory of Advanced \\ Technology for Materials Synthesis and Processing, Wuhan University of Technology, Wuhan 430070, \\ People's Republic of China \\ 5 School of Microelectronic, Fudan University, Shanghai 200433, People's Republic of China
}

\section{HIGHLIGHTS}

- Artificial optoelectronic nociceptor based on two-dimensional heterostructured all-oxide nanostructures was designed.

- Two-dimensional heterointerfaces were functionalized, and their engineering toward fabrication of artificial nociceptors was confirmed.

\begin{abstract}
Retina nociceptor, as a key sensory receptor, not only enables the transport of warning signals to the human central nervous system upon its exposure to noxious stimuli, but also triggers the motor response that minimizes potential sensitization. In this study, the capability of two-dimensional all-oxide-heterostructured artificial nociceptor as a single device with tunable properties was confirmed. Newly designed nociceptors utilize ultra-thin sub-stoichiometric $\mathrm{TiO}_{2}-\mathrm{Ga}_{2} \mathrm{O}_{3}$ heterostructures, where the thermally annealed $\mathrm{Ga}_{2} \mathrm{O}_{3}$ films play the role of charge transfer controlling component. It is discovered that the phase transformation in $\mathrm{Ga}_{2} \mathrm{O}_{3}$ is accompanied by substantial jump in conductivity, induced by thermally assisted internal redox reaction of $\mathrm{Ga}_{2} \mathrm{O}_{3}$ nanostructure during annealing. It is also experimentally confirmed that the charge transfer in alloxide heterostructures can be tuned and controlled by the heterointerfaces manipulation. Results demonstrate that the engineering of heterointerfaces of two-dimensional (2D) films enables the fabrication of either high-sensitive $\mathrm{TiO}_{2}-\mathrm{Ga}_{2} \mathrm{O}_{3}(\mathrm{Ar})$ or high-threshold $\mathrm{TiO}_{2}-\mathrm{Ga}_{2} \mathrm{O}_{3}\left(\mathrm{~N}_{2}\right)$ nociceptors. The hypersensitive nociceptor mimics the functionalities of corneal nociceptors of human eye, whereas the delayed reaction of nociceptor is similar to high-threshold nociceptive characteristics of human sensory system. The long-term stability of 2D nociceptors demonstrates the capability of heterointerfaces engineering for effective control of charge transfer at 2D heterostructured devices.
\end{abstract}

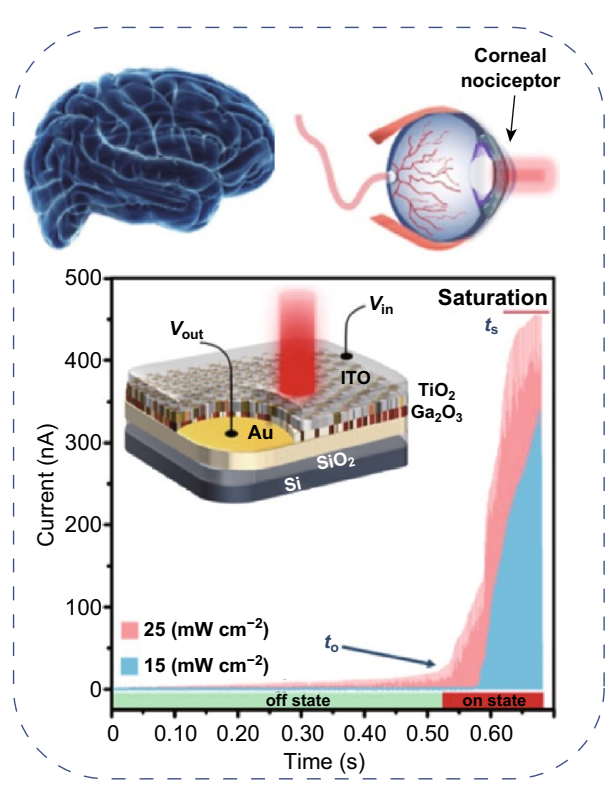

KEYWORDS 2D heterostructures; Artificial nociceptors; Bio-inspired device; Heterointerfaces engineering 


\section{Introduction}

Mimicking the human brain functionalities by using neuromorphic-based technologies is a quite essential achievement toward the development of the artificially engineered bio-inspired electronic devices [1]. The emulation of human sensory system and the sensorimotor functionalities are significant hurdles in biomimetic studies. These challenges inevitably should be responded as the substantial step toward the creation of artificial bio-inspired systems [2]. The visual processing is one of the fundamental and prominent functionalities of the human brain (Fig. 1a). Visual processing is fulfilled by outstanding features of the human's eye [3]. Eye, as the natural visual detector and processor (Fig. 1b), consists of a large number of receptors (Fig. 1c) and nociceptors (Fig. 1d). In fact, nociceptor is a key sensory receptor that recognizes noxious stimuli, which in turn generates and delivers the warning signals to the central nervous system. The brain and nervous system then generate commands to trigger the motor responses and then to minimize the potential sensitization [4]. Visual cognition is fulfilled after the processing of directly captured and

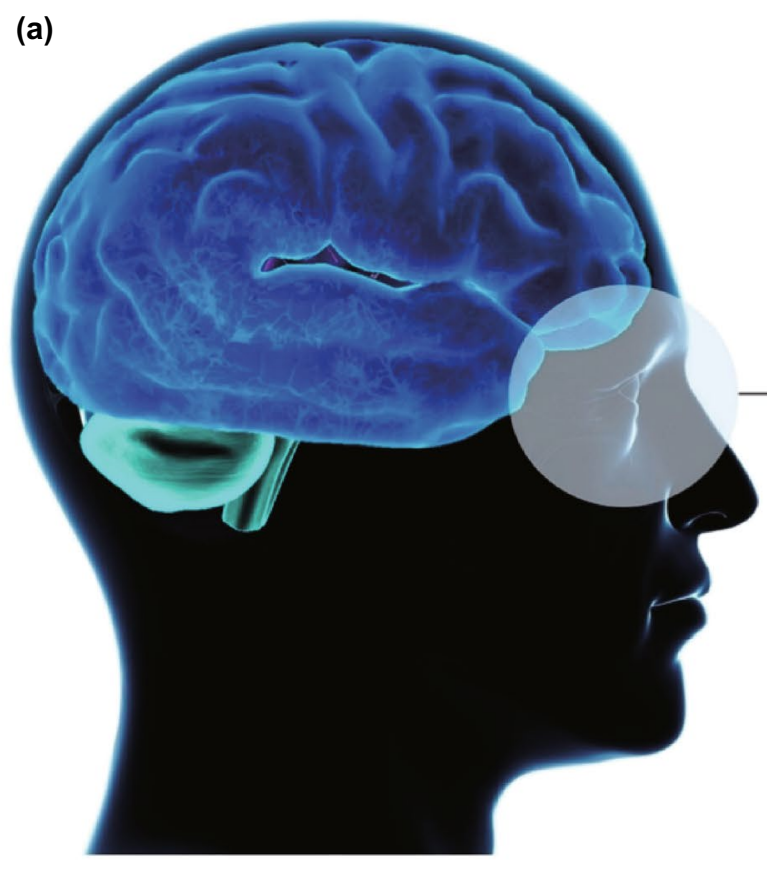

(c)
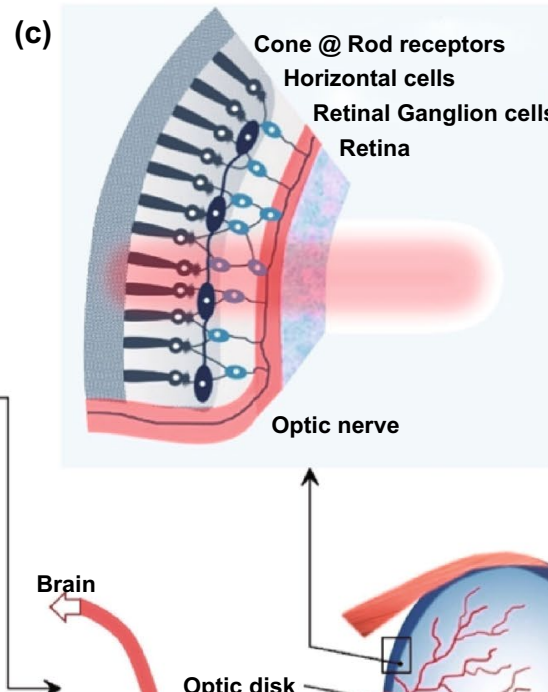

(b)

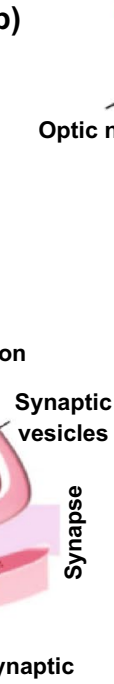

(f)

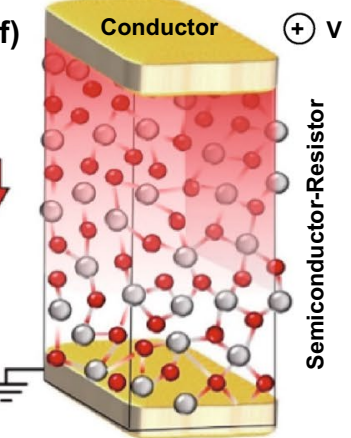

(d)

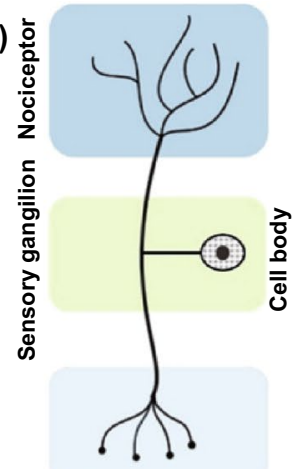

Central nervous system (e)

e)

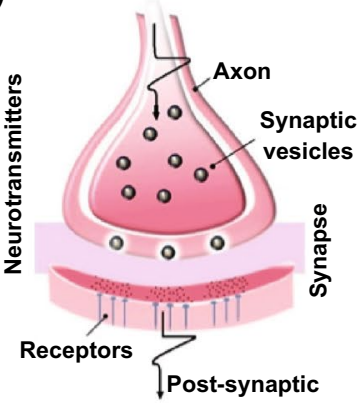

Fig. 1 The scheme of human eye receptor and nociceptor system. a Human brain as decision making unit receives the informative signals from b human eye and its sensory components including the $\mathbf{c}$ light receptors and nociceptors in retina section. $\mathbf{d}$ Typical nociceptor with its components. e Typical schematic representation of a natural synapse and $\mathbf{f}$ its artificial counterparts in conductor/semiconductor/conductor-sandwiched configuration 
detected optical stimuli by the eye's cone and rod receptors in retina [5]. Then, the generated bio-chemical voltaic signals are transferred by retinal ganglion cells to the optical nerve and finally are transmitted into the visual cortex of the brain for further processing [5].

The cornea has the highest number of nociceptors in the human eye, and the majority of the corneal nociceptors are polymodal [6]. The polymodal nociceptors are activated by the mechanical, heat, and cold stimuli and also by a large variety of exogenous irritant chemicals and endogenous inflammatory substances which are released by the damaged corneal tissues [7]. The noxious stimulations elicit the potential signals in the sensory endings of nociceptors, which are transferred and conducted by the optical nerve axons to the brain stem, and consequently evoke the nociceptive pain. Noteworthy, nociceptors play their role in two individual modes, i.e., normal and abnormal states [6]. The "threshold" and "relaxations" are two main characteristics of nociceptors in the normal state [7]. The nociceptor is in off-mode when the intensity of stimulus is lower than the threshold value, whereas the same nociceptor is turned on and reacts strongly once the stimulus intensity exceeds the threshold value. The relaxation time is another nociceptor's characteristic in the normal state, which refers to the required time span for the ultimate retrieval of nociceptor to the off-state [6,7]. Within the relaxation time span, the required intensity of stimulus for re-ignition of nociceptors is lower than the threshold values, since nociceptors are already activated. The abnormal state deals with the condition when the nociceptor is damaged. It happens once the nociceptor experiences stronger stimulus signals than its threshold limit. In this state, the nociceptor basically performs similar to the human receptor [8]. In the abnormal mode, allodynia refers to the condition that nociceptor responses to the signals even under threshold values and hyperalgesia is the condition in which the reaction to the provoking signals is stronger than that of in the normal state [8]. Typical examples of abnormal nociceptive responses are the blinking reaction of the damaged eye to the daylight or the unexpected response of the burned skin to the normal heat sources. Looking at the nervous system, the biological synapse is the fundamental base of sensorimotor system facilitating various functionalities including the pain signal transfer in the neural system (Fig. 1e). The analogous artificial nociceptive device with similar synaptic functionalities is composed of a semiconductor ultra-thin film sandwiched between two conductive layers (Fig. 1f).
In this study, we report for the first time optical artificial nociceptors built upon ultra-thin amorphous all-oxide heterostructures with ionic transport, anisotropic electrical characteristics, and ultimate transparency. Fabricated nociceptor represents the electronic memristor [9] with both insulating and semimetallic characteristics and controllable charge transfer. These capabilities in turn could facilitate the fabrication of electronic devices whose resistive functions are controlled by their nano-structural modification [10]. In this concept, sub-stoichiometric amorphous gallium oxide $\left(\mathrm{Ga}_{2} \mathrm{O}_{3}\right)$ thin films $(\sim 5.0 \mathrm{~nm})$ were rapidly thermally annealed (RTA) in either Ar or $\mathrm{N}_{2}$ atmosphere with subsequent quenching. Then, RTA gallium oxide films were utilized as the components of transparent $\mathrm{TiO}_{2}-\mathrm{Ga}_{2} \mathrm{O}_{3}$ optical memristor in heterostructured configuration. Due to the considerable electron affinity difference between the $\mathrm{Ga}_{2} \mathrm{O}_{3}$ $(4.3 \mathrm{eV})$ and $\mathrm{TiO}_{2}(1.59 \mathrm{eV})$ films, the internal driving force can facilitate the charge transfer from the $\mathrm{TiO}_{2}$ layer to the adjacent $\mathrm{Ga}_{2} \mathrm{O}_{3}$ neighbor. A charge trapping/de-trappingassociated phenomenon was characterized during the resistive switching (RS) performance of all-oxide-heterostructured devices. Phase reconfiguration in the $\mathrm{Ga}_{2} \mathrm{O}_{3}$ thin film was accompanied by the substantial jump in its conductivity induced by an internal redox reaction of amorphous structure. The distinguished charge transfer mechanism in our devices allows the reproduction of the critical nociceptive characteristics in the optically ignited heterostructured memristor. All vital nociceptor functions, including the no adaptation and sensitization, have been demonstrated in the single instrument at the same time. Furthermore, the experimental manipulation of heterointerfaces facilitated the development of either high-sensitive $\mathrm{TiO}_{2}-\mathrm{Ga}_{2} \mathrm{O}_{3}$ (Ar) or high-threshold $\mathrm{TiO}_{2}-\mathrm{Ga}_{2} \mathrm{O}_{3}\left(\mathrm{~N}_{2}\right)$ artificial nociceptors. The artificial nociceptive sensors could have several undeniable applications for conditional detection of UV- and $\gamma$-radiation in hazardous environment such as aerospace technologies.

\section{Experimental}

\subsection{Fabrication and Characterization of Nociceptors}

The Au electrodes were patterned by electron beam (EB) evaporation on the $\mathrm{SiO}_{2} / \mathrm{Si}$ substrate. Plasma-enhanced atomic layer deposition (PE-ALD) was employed to deposit 5.0-nm-thick gallium oxide films over Au electrodes. The 
tris (2,2,6,6-tetramethyl-3,5-heptanedionato) gallium (III), [Ga(TMHD) ${ }_{3}$ ] (Strem Chemicals, 99\%), and $\mathrm{O}_{2}$ plasma were used in PE-ALD process. For RTA treatment, the $\mathrm{Au}-\mathrm{Ga}_{2} \mathrm{O}_{3}$ electrodes were thermally annealed in controlled condition under $\mathrm{Ar}$ or $\mathrm{N}_{2}$ atmosphere. The heating rate was designed to be $60{ }^{\circ} \mathrm{C} \mathrm{min}^{-1}$. The samples were hold for $10 \mathrm{~min}$ at the designed temperatures and then finally quenched to the room temperature by the same rate. The 20.0-nm-thick amorphous $\mathrm{TiO}_{2}$ films were then deposited by PE-ALD (tetrakis dimethylamino titanium and $\mathrm{O}_{2}$ plasma) over the RTA gallium oxide films to develop all-oxide heterostructures. At the final stage, Pt or indium tin oxide (ITO) top electrodes were fabricated over all-oxide-heterostructured films.

\subsection{Materials Characterization}

Various characterization techniques were employed for investigation of the material properties. The Raman measurements were used individually by continuous laser beam of Raman ( $\lambda=750 \mathrm{~nm}$, HORIBA micro-Raman, Lab Ram ARAMIS) to characterize ultra-thin films. To investigate the memristive behavior of heterostructured films, Raman measurements were individually performed at the zero bias and then at the HRS mode of memristor device. XPS studies were extensively used to evaluate the chemical compositions, percentage of elements, and vacancies in the RTA and heterostructured films as well as to determine the band alignment at semiconductor heterointerfaces (XPS, Thermo Scientific theta probe). The absorbance and reflectance spectra of samples were measured using UV-visible diffused reflectance spectrometer (Shimadzu, UV-Vis 2600) to evaluate the bandgap of heterostructured films. To this aim, all films were deposited on the highly transparent glass substrates. The field emission scanning electron microscope (FESEM JEOL-7800F) was used for measurement of photoluminescence characteristics. Hall-effect measurements (Ecopia) were employed to measure the conductivity of the samples. Kelvin probe force microscopy was used to measure the surface potential of samples.

\subsection{Memristor and Nociceptor Devices}

Autolab Metrohm (PGSTAT204) instrument was used to evaluate the performance of memristors. Tunable LED laser driver $(\lambda=360 \mathrm{~nm})$ in combination with the Autolab signal analyzer (PGSTAT204) was employed to measure the photoresponsive and nociceptive responses of devices and to precisely design and pattern optical pulses.

\section{Results and Discussion}

\subsection{Structural Properties}

It was observed that the RTA of $\mathrm{Ga}_{2} \mathrm{O}_{3}$ film in Ar and $\mathrm{N}_{2}$ atmospheres (Fig. 2a) and the subsequent quenching were accompanied by the phase transformation [10]. The Raman spectra (Fig. 2b) of the samples show the characteristic peaks of $\mathrm{GaO}$ bonding. Specifically, the observed low-frequency modes of $208 \mathrm{~cm}^{-1}\left(\mathrm{~A}_{\mathrm{g}}\right), 170 \mathrm{~cm}^{-1}\left(\mathrm{~A}_{\mathrm{g}}\right)$, and $145 \mathrm{~cm}^{-1}\left(\mathrm{~B}_{\mathrm{g}}\right)$ are the characteristic vibration modes for liberation and vibration of tetrahedral-octahedra chain in $\beta-\mathrm{Ga}_{2} \mathrm{O}_{3}$ [11]. The other observed peak at $415 \mathrm{~cm}^{-1}$ is assigned to the in-plane octahedra-related optical mode of $\mathrm{Ga}_{2} \mathrm{O}_{6}$ [11]. The $\mathrm{A}_{\mathrm{g}}$ characteristic peaks at 634 and $679 \mathrm{~cm}^{-1}$ are attributed to the tetrahedra-related optical modes of $\mathrm{GaO}_{4}$, respectively [11]. The intensity of characteristic modes of $\mathrm{GaO}$ bonding increased after RTA. The characteristic $\mathrm{E}_{2}$ (high) Raman mode of $\mathrm{GaN}$ was also detected at $548 \mathrm{~cm}^{-1}$ in $\mathrm{Ga}_{2} \mathrm{O}_{3}$ annealed in $\mathrm{N}_{2}$ atmosphere confirming the successful nitrogen incorporation in $\mathrm{Ga}_{2} \mathrm{O}_{3}$ [12]. The RTA process of as-deposited $\mathrm{Ga}_{2} \mathrm{O}_{3}$ in $\mathrm{N}_{2}$ atmosphere was accompanied by the red shift of $\mathrm{A}_{\mathrm{g}}$ characteristic peaks of $\mathrm{Ga}_{2} \mathrm{O}_{3}$, which can be attributed to the crystalline state of RTA $\mathrm{Ga}_{2} \mathrm{O}_{3}$ film. From the morphological point of view, the RTA resulted in the visible growth of $\mathrm{Ga}_{2} \mathrm{O}_{3}$ grains (Fig. 2d1-d4). One of the most notable observations in our study is the prominent alteration of bandgap energy $\left(E_{\mathrm{g}}\right)$ of $\mathrm{Ga}_{2} \mathrm{O}_{3}$ thin films. The photoluminescence (PL) measurements (Fig. 2e) accompanied by calculated bandgap (Fig. 2f) confirmed the decrease of $E_{\mathrm{g}}$ from 4.47 to $3.89 \mathrm{eV}$, as the thickness of $\mathrm{Ga}_{2} \mathrm{O}_{3}$ was reduced from 20.0 to $\sim 5.0 \mathrm{~nm}$ (Fig. $\mathrm{S} 1 \mathrm{a})$. It can be attributed to the effect of strain-related factors on $E_{\mathrm{g}}$ of ultra-thin films [12] and to the stoichiometric changes of $\mathrm{Ga}_{2} \mathrm{O}_{3}$ films [13]. The $E_{\mathrm{g}}$ values of RTA-treated $\mathrm{Ga}_{2} \mathrm{O}_{3}$ films in $\mathrm{Ar}(3.22 \mathrm{eV})$ and $\mathrm{N}_{2}(3.39 \mathrm{eV})$ atmosphere are smaller than $E_{\mathrm{g}}$ of as-deposited $\mathrm{Ga}_{2} \mathrm{O}_{3}$ films $(3.89 \mathrm{eV})$ (Figs. 2e, f and S1b, c). Furthermore, the other absorption tails were detected in PL spectra of as-deposited and RTA $\mathrm{Ga}_{2} \mathrm{O}_{3}$ films at wavelengths of $400500 \mathrm{~nm}$. It is expected that the visible light PL responsivity is attributed to the 


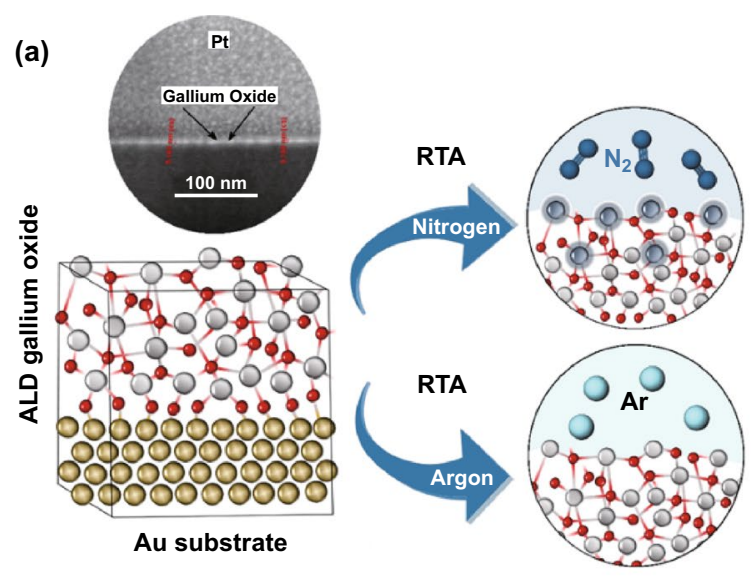

(d)
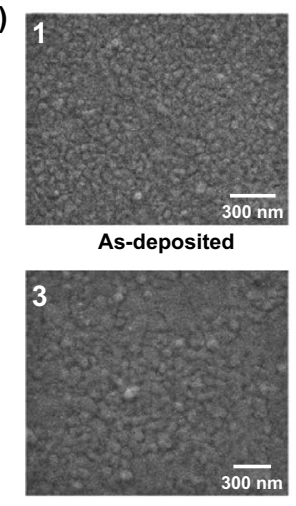

$\operatorname{RTA}\left(\mathrm{N}_{2}-450^{\circ} \mathrm{C}\right)$ \& Quenching

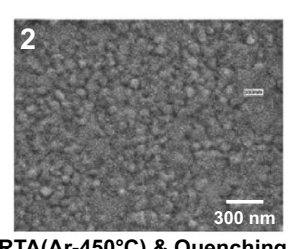

$\operatorname{RTA}\left(\operatorname{Ar}-450^{\circ} \mathrm{C}\right) \&$ Quenching

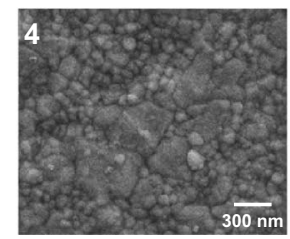

$\operatorname{RTA}\left(\mathrm{N}_{2}-600^{\circ} \mathrm{C}\right)$ \& Quenching
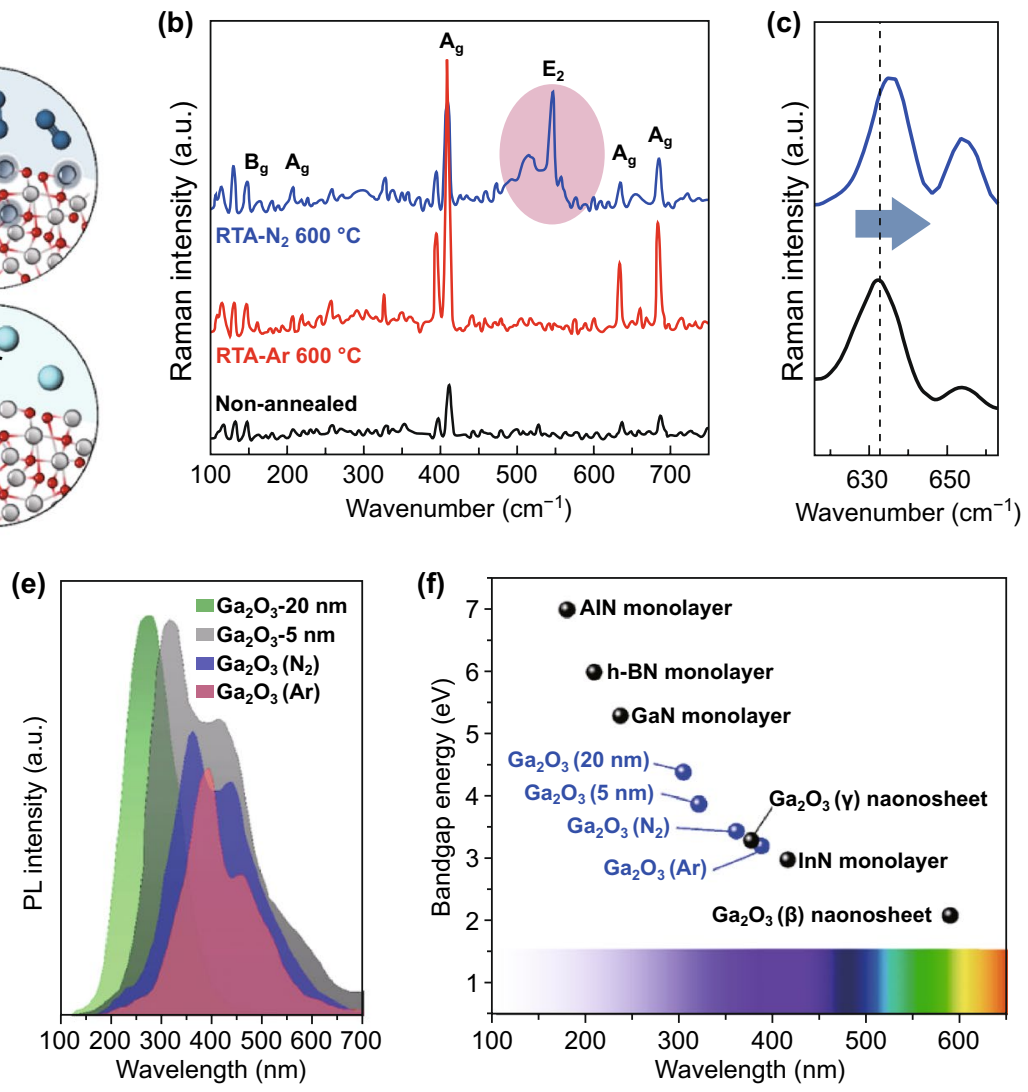

Fig. 2 Schematic of RTA treatment accompanied by characterization results of ultra-thin heterostructured films. a Graphical scheme for RTA of 5-nm-thick gallium oxide film in Ar and $\mathrm{N}_{2}$ atmosphere. b Typical Raman characteristics of RTA-treated gallium oxide films in Ar and $\mathrm{N}_{2}$ atmosphere, $\mathbf{c}$ Raman shifts and d FESEM microstructural observations. e Photoluminescence spectra of as-deposited and RTA-treated gallium oxide films. $\mathbf{f}$ Comparative diagram of $E_{\mathrm{g}}$ of selected two-dimensional (2D) metal nitrides accompanied by the results of present study

extra states in the bandgap of $\mathrm{Ga}_{2} \mathrm{O}_{3}$ caused by the gallium excess in sub-stoichiometric films [10,14]. It seems that the UV categorized PL peaks in ultra-thin $\mathrm{Ga}_{2} \mathrm{O}_{3}$ films are also related to the crystallization of $\beta-\mathrm{Ga}_{2} \mathrm{O}_{3}$ in amorphous films (bandgap $3.89 \mathrm{eV}$ ). This eventually leads to the dual bandgap properties, which is typical characteristic of the composite materials (Fig. S1). The plot in Fig. 2f represents a comparative scheme of the $E_{\mathrm{g}}$ values of various ultra-thin 2D nitrides $[11,15]$. Graph demonstrates that the RTA-treated and quenched ultra-thin $\mathrm{Ga}_{2} \mathrm{O}_{3}$ samples can be considered as candidates for the tunable optoelectronic applications. The bandgap of the as-deposited $\mathrm{Ga}_{2} \mathrm{O}_{3}$ ultra-thin film decreased after RTA in $\mathrm{N}_{2}$ atmosphere. The observation of absorption edge in transmittance spectra of $\mathrm{N}_{2}$-doped $\mathrm{Ga}_{2} \mathrm{O}_{3}$ film (Fig. S2) suggests the dissociation of nitrogen anions into $\mathrm{Ga}_{2} \mathrm{O}_{3}$ structure. This implies that the introduction of ionic nitrogen into $\mathrm{Ga}_{2} \mathrm{O}_{3}$ considerably altered its band structure.
The origin of the decreased bandgap was attributed to the $\mathrm{N}$ acceptor states in the bandgap of $\mathrm{Ga}_{2} \mathrm{O}_{3}$ [16-18]. The other evidences about bandgap alteration of nitrogen-doped ultrathin $\mathrm{Ga}_{2} \mathrm{O}_{3}$ film are discussed in the next section.

\subsection{Mechanism of Phase Transition}

Figure 3a shows the results of conductivity measurements versus the RTA processing temperature. All measurements were performed after rapid quenching to investigate the final structural phases of materials. It was observed that asdeposited $\mathrm{Ga}_{2} \mathrm{O}_{3}$ samples are in insulating mode, whereas for the samples annealed at $450{ }^{\circ} \mathrm{C}$, the conductivity is still low $\left(\sim 10^{-1} \mathrm{~S} \mathrm{~cm}^{-1}\right)$ and transparency is as high as $84 \%$ in the visible region (Fig. S2). Noteworthy, measurements confirmed a profound increment of conductivity (Fig. 3a) at the RTA temperatures above $525^{\circ} \mathrm{C}$, where the conductivity 


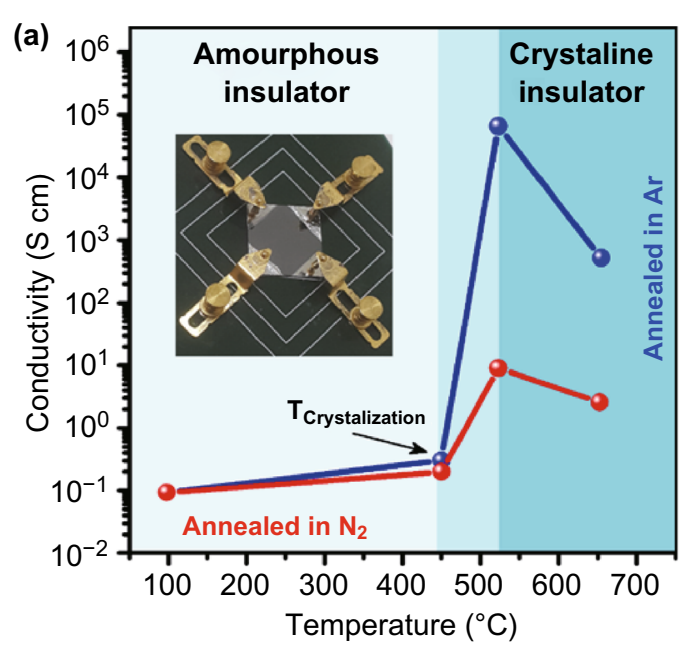

(b) Amorphous
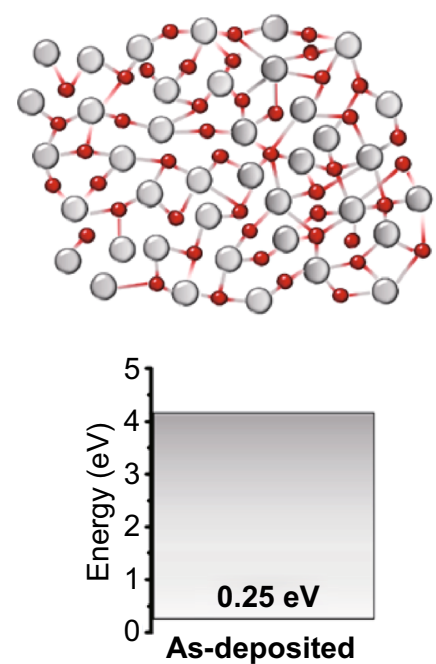

(c) Amorphous + Crystaline phase
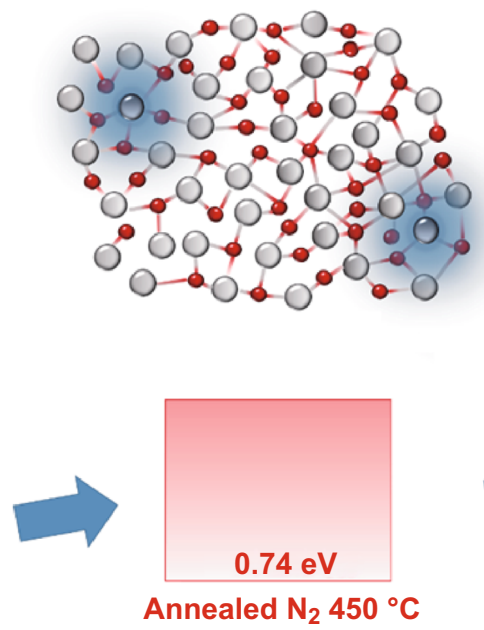

(d) Amorphous + Crystaline phase
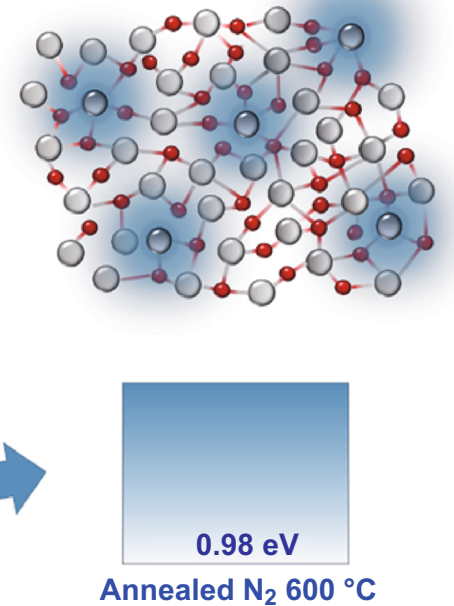

Fig. 3 The results of electrical conductivity measurements and graphical scheme of phase transformation of gallium oxide film during RTA treatment and their XPS measurements. a Conductivity variation of gallium oxide thin films after RTA in Ar and $\mathrm{N}_{2}$ atmosphere. The conductivity was measured after quenching of samples from high temperatures. b-d The phase transformation in gallium oxide films during RTA treatment. The as-deposited films are amorphous until the crystallization temperature at which the nucleation of crystalline stoichiometric $\mathrm{Ga}_{2} \mathrm{O}_{3}$ nucleus sites occurs [10]. It is accompanied by the increase in $\mathrm{Ga}$ excess in remained amorphous phase and the evolution of conductivity of thin films

(RTA in Ar) is about six orders of magnitude higher than that of the as-deposited samples. The observed jump in conductivity value is incredible. However, further annealing at higher temperature is accompanied by the conductivity decline. These facts reinforce the hypothesis that our ultra-thin films have experienced the phase transformation from insulator to semiconductor and then to semimetallic structures after RTA and fast quenching treatments [10]. A model has been introduced which relates the conductivity increment phenomenon to the nucleation of crystalline and stoichiometric $\mathrm{Ga}_{2} \mathrm{O}_{3}$ nucleus in amorphous gallium oxide [10] (Fig. 3b-d). It is suggested that further nucleation of stoichiometric $\mathrm{Ga}_{2} \mathrm{O}_{3}$ phases is accompanied by the increase in metallic content in ultra-thin films owing to the initial Ga excess in the sub-stoichiometric microstructure. It is expected that the $\mathrm{Ga}$ interstitials enhance the number of donors in amorphous $\mathrm{Ga}_{2} \mathrm{O}_{3}$. Therefore, the remained amorphous $\mathrm{Ga}_{2} \mathrm{O}_{3}$ in RTA sample is heavily donor-doped semiconductor. It was suggested that $\mathrm{Ga}$ excess increases the possibility of formation of new electronic states above the 
valence state of amorphous $\mathrm{Ga}_{2} \mathrm{O}_{3}$ [10]. It is confirmed that the number of states in the optical bandgap of amorphous $\mathrm{Ga}_{2} \mathrm{O}_{3}$ increases by enhancement of $\mathrm{Ga}$ content in microstructure. It consequently results in the decrease in energy gap between the highest occupied states and the conduction band $[10,19]$. Our observations also confirmed the bandgap decrease (Fig. S1) and alteration of the valence band maximum (VBM) of the annealed samples in Ar atmosphere (Fig. S3).

In the case of RTA of $\mathrm{Ga}_{2} \mathrm{O}_{3}$ film in $\mathrm{N}_{2}$, Raman measurements depicted strong characteristic peak of $\mathrm{GaN}$ (Fig. 2b). The conductivity jump in RTA $\left(\mathrm{N}_{2}\right) \mathrm{Ga}_{2} \mathrm{O}_{3}$ sample is only two times higher than the conductivity increase in as-deposited $\mathrm{Ga}_{2} \mathrm{O}_{3}$ film, which is much smaller than that of sample annealed in Ar atmosphere (Fig. 3a). Typical chemical composition in the stoichiometric $\mathrm{Ga}_{2} \mathrm{O}_{3}$ is $\mathrm{Ga}: \mathrm{O}=0.40: 0.60$. However, the chemical composition of as-deposited sample was 0.46:0.54. Using XPS results, the composition of the RTA $\left(\mathrm{N}_{2}\right)$ samples at $450{ }^{\circ} \mathrm{C}$ is obtained as $\mathrm{Ga}: \mathrm{O}: \mathrm{N}=0.59: 0.35: 0.06$, which also demonstrates the $\mathrm{Ga}$ excess in the annealed structures. It is expected that the nitrogen is substituted for oxygen atoms in the $\mathrm{Ga}_{2} \mathrm{O}_{3}$ structure and plays its role as the acceptor atom with subsequent partial compensation of the donor effects [10, 16]. Owning to this partial donor compensation, the bandgap of RTA $\left(\mathrm{N}_{2}\right)$ samples is larger than that of RTA (Ar) samples (Fig. 2f). Nevertheless, the bandgap is decreased and the visible light responsivity is facilitated due to the Ga excess in the remained amorphous phase [10]. On the contrary, typical composition of the samples annealed $\left(\mathrm{N}_{2}-600{ }^{\circ} \mathrm{C}\right)$ is $\mathrm{Ga}: \mathrm{O}: \mathrm{N}=0.67: 0.24: 0.09$, which displays higher level of $\mathrm{Ga}$ excess and $\mathrm{N}_{2}$ doping in ultra-thin films. The most plausible explanation for higher $\mathrm{Ga}$ excess can be related to higher number of crystalline nucleus sites at higher RTA temperature. This phenomenon consequently resulted in the increase in Ga excess in ultra-thin $\mathrm{Ga}_{2} \mathrm{O}_{3}$ film. After annealing in $\mathrm{N}_{2}$ atmosphere, the VBM was increased to higher binding energies, as it is graphically depicted (Fig. 3b-d). The XPS results in Fig. 4a show the increase in VBM to higher binding energies after annealing in $\mathrm{N}_{2}$ atmosphere at higher annealing temperature. It can be related to higher concentration of $\mathrm{N}_{2}$ acceptor in the structure. The O1s corelevel spectra of $\mathrm{N}_{2}$-annealed samples (Fig. 4b) shifted to lower binding energies. It is because of replacement of $\mathrm{N}_{2}$ atoms (with low electronegativity) with $\mathrm{O}_{2}$ atoms (with high electronegativity) in $\mathrm{Ga}_{2} \mathrm{O}_{3}$ structure.
The deconvoluted O1s spectra in Fig. S4 depict the characteristic of $\mathrm{Ga}-\mathrm{O}$ at $530.7 \mathrm{eV}$. The relative intensity of $\mathrm{Ga}-\mathrm{O}$ deconvoluted peak is reversely proportional to the concentration of oxygen vacancy in the $\mathrm{Ga}_{2} \mathrm{O}_{3}$ films. Figure $4 \mathrm{c}$ shows the values of relative proportional component (RPC) of vacancies which are calculated by using $\mathrm{Ga}-\mathrm{O}$ peak intensities in the RTA $\mathrm{Ga}_{2} \mathrm{O}_{3}$ samples. The improved nitrogen doping at higher annealing temperature is confirmed when the proportional intensity of $\mathrm{Ga}-\mathrm{O}$ bonds increased at higher RTA temperature. It is also accompanied by the decreased component of oxygen vacancies. On the other hand, the decrease in intensity of Ga3d (Fig. 4d) and Ga2p (Fig. S5) confirms the incorporation of $\mathrm{N}_{2}$ in the $\mathrm{Ga}_{2} \mathrm{O}_{3}$ structure. It is also accompanied by the decrease in proportional $\mathrm{Ga}-\mathrm{O}$ bonds intensity. The N1s core-level spectrum at $397 \mathrm{eV}$ (Fig. 4e) arises from the oxygen substitution by $\mathrm{N}$ atoms (acceptor atoms) [12,20], which is the XPS characteristic of the $\mathrm{Ga}-\mathrm{N}$ bonding [10]. Without nitrogen, the oxygen and $\mathrm{Ga}$ form $\mathrm{Ga}-\mathrm{O}$ bonding. The presence of $\mathrm{N}_{2}$ in annealing process facilitates the formation of $\mathrm{Ga}-\mathrm{N}$ and $\mathrm{Ga}-\mathrm{N}-\mathrm{O}$ bonds. Lower electronegativity of $\mathrm{N}$ (3.0) compared with higher electronegativity of $\mathrm{O}$ (3.5) leads to the gradual shift of $\mathrm{O} 1 \mathrm{~s}$ and Ga3d peaks to lower binding energies in XPS spectra (Fig. 4b, d). Considering larger ionicity of $\mathrm{Ga}-\mathrm{O}$ bonds than that of $\mathrm{Ga}-\mathrm{N}$ bonds, the decrease in optical bandgap was predicted by incorporation of nitrogen atoms into $\mathrm{Ga}-\mathrm{O}$ structure [16]. The $\mathrm{Ga}-\mathrm{N}$ characteristic bonding was also observed in the Raman spectra (Figs. $2 b$ and S6). The lattice distortion is expected by incorporation of nitrogen atoms into $\mathrm{Ga}-\mathrm{O}$ lattice structure $[17,18]$. A larger d-spacing was reported due to doping of $\mathrm{Ga}_{2} \mathrm{O}_{3}$ film by $\mathrm{N}_{2}$ atoms which resulted in the narrower bandgap [17, 18].

\subsection{Memristor Devices}

The control of the charge transfer phenomenon in the memristor devices is the fundamental bases of neuromorphicbased technology [21]. It is expected that the high-bandgap heterostructured films can fulfill the requirement of neuromorphic units since the charge transfer can be tuned and controlled by the manipulation of the heterointerfaces [22]. Furthermore, both transparency and electronegativity differences between the heterostructured components can facilitate the development of bio-inspired optoresponsive 


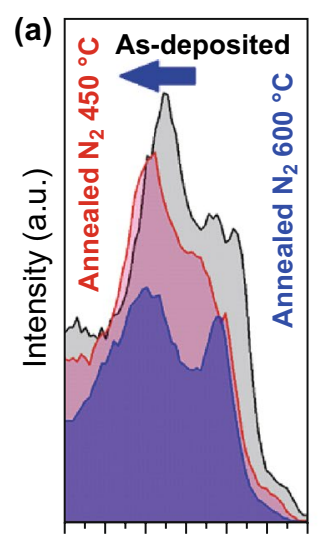

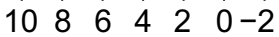
Binding energy $(\mathrm{eV})$
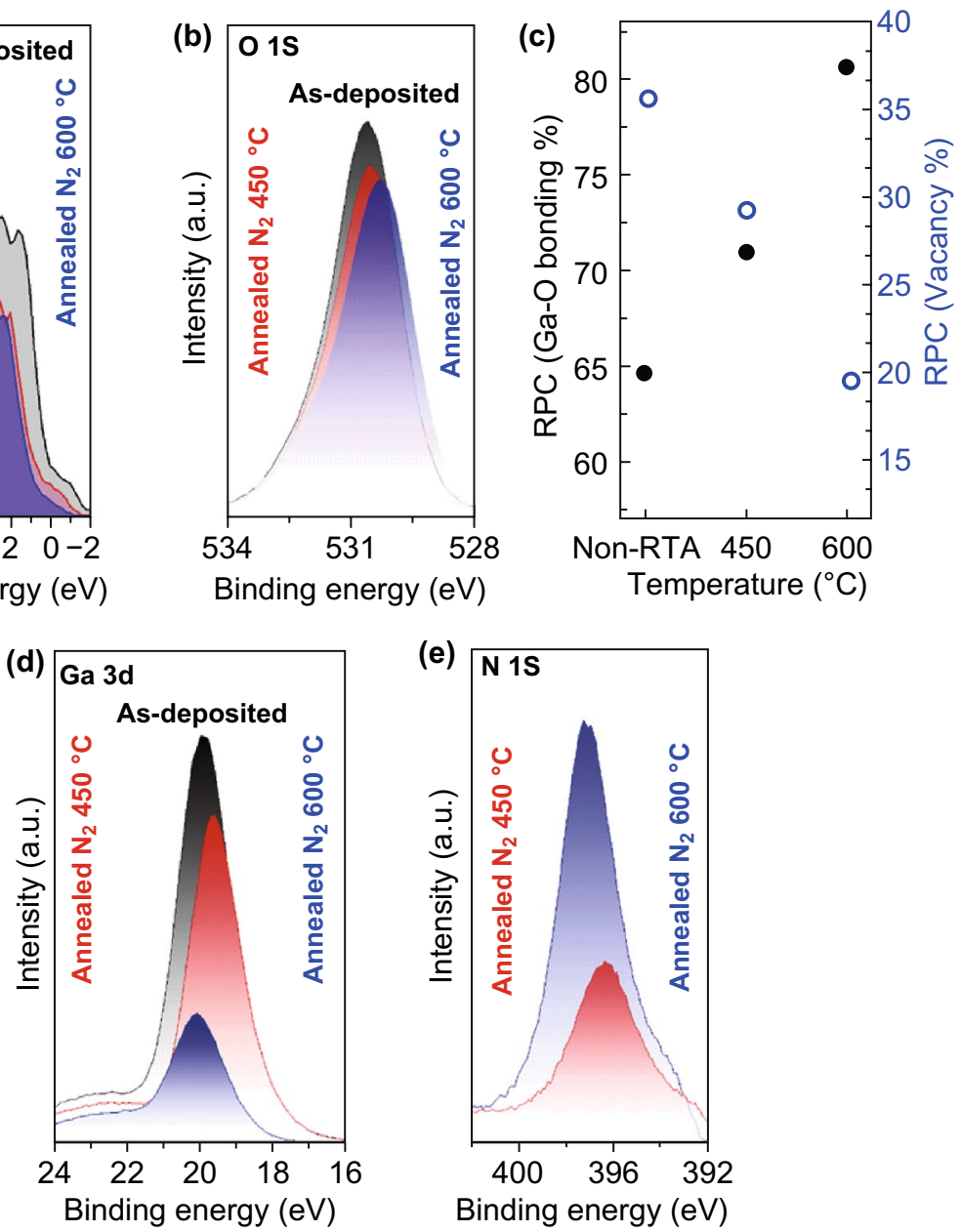

Fig. 4 XPS core-level spectra and VBM of $\mathrm{N}_{2}$-doped $\mathrm{Ga}_{2} \mathrm{O}_{3}$ films. a RTA process is resulted in the alteration of bandgap alignment in gallium oxide films where a higher RTA temperature in $\mathrm{N}_{2}$ atmosphere was accompanied by the increase in VBM. b Analytical analysis of O1s XPS characteristics of samples, $\mathbf{c}$ variation of percentage of $\mathrm{Ga}-\mathrm{O}$ bonding and oxygen vacancy in RTA samples. $\mathbf{d}$ XPS characteristics of Ga3d and $\mathbf{e}$ N1s in RTA samples

instrument. In doing so, 20.0-nm-thick $\mathrm{TiO}_{2}$ film was deposited by ALD on as-deposited and RTA $\mathrm{Ga}_{2} \mathrm{O}_{3}(5.0 \mathrm{~nm})$ films to fabricate $\mathrm{Pt} / \mathrm{TiO}_{2}-\mathrm{Ga}_{2} \mathrm{O}_{3} / \mathrm{Au}$ devices. The Raman studies demonstrate the vibration modes of $\mathrm{Ga}_{2} \mathrm{O}_{3}$ and $\mathrm{TiO}_{2}$ in heterostructured films (Fig. S7). To understand the charge transfer mechanisms, the current-voltage $(I-V)$ measurements were performed under dark condition, while the $\mathrm{Pt} / \mathrm{TiO}_{2}$ was biased and $\mathrm{Au} / \mathrm{Ga}_{2} \mathrm{O}_{3}$ was grounded. Typical bipolar switching curves were obtained during the sweeping from $0 \rightarrow 1 \rightarrow 0 \rightarrow-1 \rightarrow 0$ for $\mathrm{Au} / \mathrm{Ga}_{2} \mathrm{O}_{3}-\mathrm{TiO}_{2} / \mathrm{Pt}$ and $\mathrm{Au} /$ $\mathrm{Ga}_{2} \mathrm{O}_{3}(\mathrm{Ar})-\mathrm{TiO}_{2} / \mathrm{Pt}$ (Fig. 5a). Fragile loop openings were observed in both devices. The driven current from the $\mathrm{Au} /$ $\mathrm{Ga}_{2} \mathrm{O}_{3}\left(\mathrm{Ar}-600{ }^{\circ} \mathrm{C}\right)-\mathrm{TiO}_{2} / \mathrm{Pt}$ sample is tangibly higher than that of as-deposited $\mathrm{TiO}_{2}-\mathrm{Ga}_{2} \mathrm{O}_{3}$ samples (Fig. 5a). The plausible explanation can be attributed to higher level of $\mathrm{Ga}$ excess in RTA (Ar- $600{ }^{\circ} \mathrm{C}$ ) samples compared with that of as-deposited $\mathrm{Ga}_{2} \mathrm{O}_{3}$. It also can be related to the improved crystallinity of $\mathrm{Ga}_{2} \mathrm{O}_{3}$ film after RTA process. The phasetransformed $\mathrm{Ga}_{2} \mathrm{O}_{3}$ with higher level of $\mathrm{Ga}$ excess performs as high-conductive layer between $\mathrm{TiO}_{2}$ film and Au electrode (Note S1 and Fig. S8). The migration of oxygen vacancies in thicker $\mathrm{TiO}_{2}$ layer and charge trapping phenomenon at the heterostructured interface are the most plausible explanations for the resistive behavior of samples [22, 23]. In fact, the thermal annealing of the heterostructured film in oxygen atmosphere has resulted in the deterioration of RS characteristics of them. It can be attributed to the decline of vacancyrelated charge trapping sites [24] (Fig. S9). However, still 

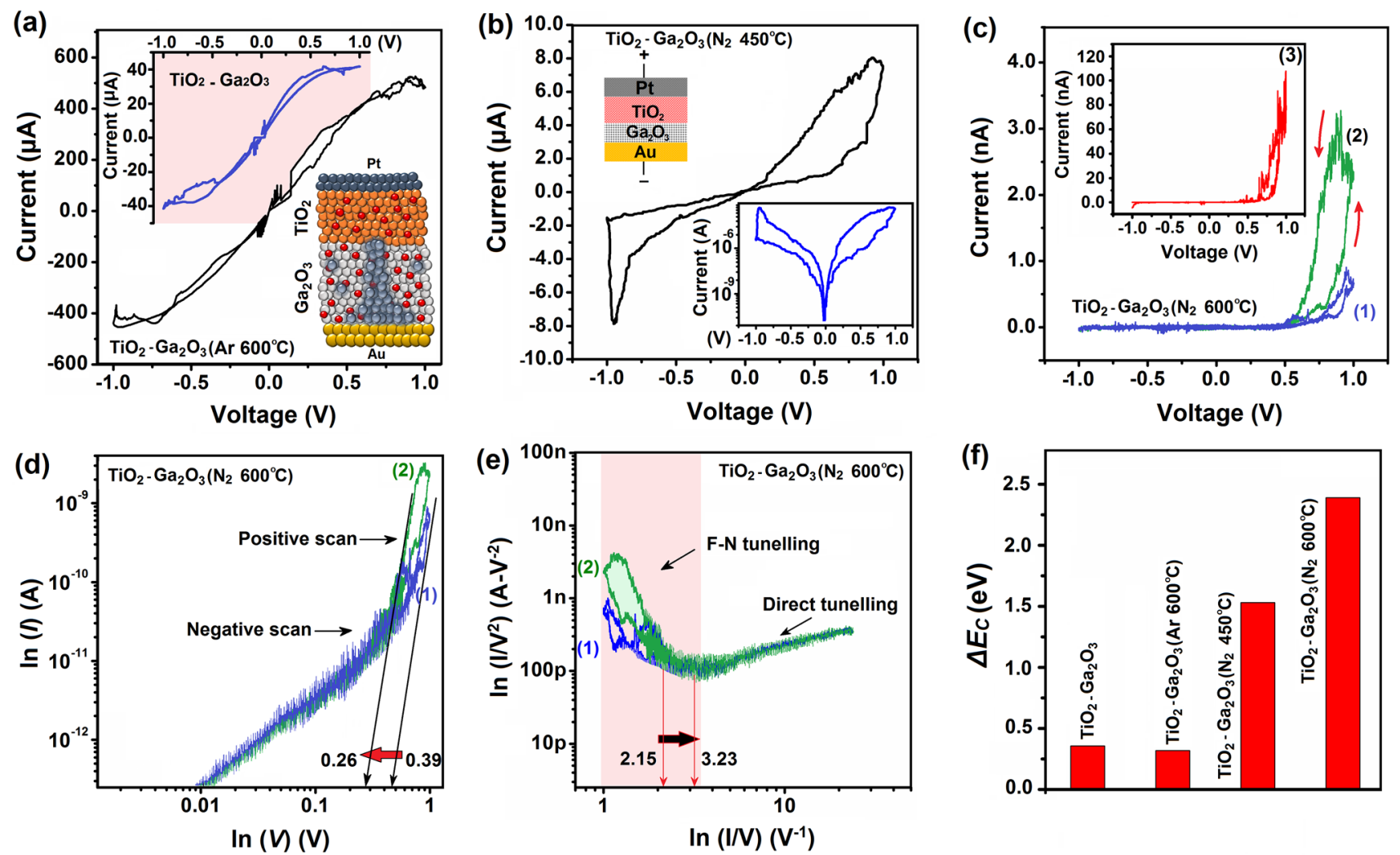

Fig. 5 The electrical characterization of fabricated memristor devices accompanied by the characterization of resistive behavior of them. a Typical $I-V$ curves of $\mathrm{Pt} / \mathrm{TiO}_{2}-\mathrm{Ga}_{2} \mathrm{O}_{3} / \mathrm{Au}$ and $\mathrm{Pt} / \mathrm{TiO}_{2}-\mathrm{Ga}_{2} \mathrm{O}_{3}\left(\mathrm{Ar}-600{ }^{\circ} \mathrm{C}\right) / \mathrm{Au}$, b Pt/TiO $-\mathrm{Ga}_{2} \mathrm{O}_{3}\left(\mathrm{~N}_{2}-450{ }^{\circ} \mathrm{C}\right) / \mathrm{Au}, \mathbf{c ~ P t} / \mathrm{TiO}_{2}-\mathrm{Ga} \mathrm{O}_{3}\left(\mathrm{~N}_{2}-600{ }^{\circ} \mathrm{C}\right) /$ $\mathrm{Au}$ memristor devices for three cycles. d Logarithmic scale $I-V$ characteristics for two cyclic voltammetry of $\mathrm{Pt} / \mathrm{TiO}_{2}-\mathrm{Ga}_{2} \mathrm{O}_{3}\left(\mathrm{~N}_{2}-600{ }^{\circ} \mathrm{C}\right) / \mathrm{Au}$ memristor devices. e Logarithmic scale of $I / V^{2}$ versus the $I / V$ curves of the same device. The transition from direct tunneling to $\mathrm{F}-\mathrm{N}$ tunneling is depicted. $\mathbf{f} \Delta E_{\mathrm{c}}$ of fabricated heterostructured memristor devices

the memristive switching and performance of $\mathrm{Ga}_{2} \mathrm{O}_{3}-\mathrm{TiO}_{2}$ and $\mathrm{Ga}_{2} \mathrm{O}_{3}\left(\mathrm{Ar}-600{ }^{\circ} \mathrm{C}\right)-\mathrm{TiO}_{2}$ devices are not considerable (Fig. 5a). The heterointerface engineering was employed to alter the charge transfer mechanism between two semiconductor components and to improve the memristive characteristics of heterostructured semiconductor devices. To this aim, ultra-thin $\mathrm{Ga}_{2} \mathrm{O}_{3}$ film was annealed in nitrogen atmosphere to manipulate the heterointerfaces band alignment and also affect the charge trapping and transfer mechanisms at $\mathrm{Ga}_{2} \mathrm{O}_{3}-\mathrm{TiO}_{2}$ heterointerfaces.

The cyclic $I-V$ curves for $\mathrm{Pt} / \mathrm{TiO}_{2}-\mathrm{Ga}_{2} \mathrm{O}_{3}\left(\mathrm{~N}_{2}-450{ }^{\circ} \mathrm{C}\right) / \mathrm{Au}$ device (Fig. 5b) showed considerable loop opening. During $I-V$ sweeping, the cell was set to the low-resistance state (LRS) at the positive voltage and reset to the high-resistance state (HRS) at the negative voltage. This process is well known as the counter-eight-wise-switching mechanism [25]. A considerable improvement of HRS/LRS ratio was observed after modification of $\mathrm{TiO}_{2}-\mathrm{Ga}_{2} \mathrm{O}_{3}$ semiconductor heterointerfaces by incorporation of $\mathrm{N}_{2}$ atoms into $\mathrm{Ga}_{2} \mathrm{O}_{3}$ film. While the current and resistance values changed gradually for the forward biased, they both changed abruptly at the reverse-biased voltage (logarithmic plot of $I-V$ in Figs. $5 \mathrm{~b}$ and S10). The memristive behavior of $\mathrm{Pt} / \mathrm{TiO}_{2}-\mathrm{Ga}_{2} \mathrm{O}_{3}\left(\mathrm{~N}_{2}\right) /$ $\mathrm{Au}$ device was tangibly different with the performance of $\mathrm{TiO}_{2} / \mathrm{Pt} / \mathrm{Ga}_{2} \mathrm{O}_{3}(\mathrm{Ar}) / \mathrm{Au}$ samples. Strong rectification behavior (Fig. $5 \mathrm{c}$ ) was observed during the cyclic $I-V$ test of $\mathrm{TiO}_{2}-\mathrm{Ga}_{2} \mathrm{O}_{3}\left(\mathrm{~N}_{2}-600{ }^{\circ} \mathrm{C}\right)$, which is the characteristic of the development of type-II heterojunctions [25]. The loop opening, as characteristic of the charge trapping/de-trapping, is observed again. Comparing the first cyclic loop, it was found that the driven current for $\mathrm{TiO}_{2}-\mathrm{Ga}_{2} \mathrm{O}_{3}\left(\mathrm{~N}_{2}\right)$ was tangibly lower than that for the $\mathrm{TiO}_{2}-\mathrm{Ga}_{2} \mathrm{O}_{3}$ (Ar). It was also discovered that the driven current from $\mathrm{Pt} / \mathrm{TiO}_{2}-\mathrm{Ga}_{2} \mathrm{O}_{3}$ $\left(\mathrm{N}_{2}-600{ }^{\circ} \mathrm{C}\right.$ )/Au device (Fig. $5 \mathrm{c}$ ) was tangibly lower than that of the same device annealed at $450{ }^{\circ} \mathrm{C}$ (Fig. 5b). Pt/ $\mathrm{TiO}_{2}-\mathrm{Ga}_{2} \mathrm{O}_{3}\left(\mathrm{~N}_{2}-600{ }^{\circ} \mathrm{C}\right) / \mathrm{Au}$ heterointerfaces also showed 
the rectification behavior. It can be understood by investigation of charge trapping mechanisms and determination of energy band alignment at semiconductor heterointerfaces. To realize the underlying dynamics of the charge transfer across the heterostructure, double logarithmic scale $I-V$ curves of $\mathrm{Pt} / \mathrm{TiO}_{2}-\mathrm{Ga}_{2} \mathrm{O}_{3}\left(\mathrm{~N}_{2}-600{ }^{\circ} \mathrm{C}\right) / \mathrm{Au}$ devices are plotted at the several cyclic loops (Fig. 5d). The slope value close to one is the characteristic of the ohmic-like conductance $(I \propto V)$ at lower positive bias voltage, which is caused by the thermally generated free carriers [26]. Trap-filled-limited voltage $\left(V_{\mathrm{th}}\right)$ shifted from $0.39 \mathrm{~V}$ at the first cycle down to $0.26 \mathrm{~V}$ at the second cycle (Fig. $5 \mathrm{~d}$ ). Thus, it is estimated that the trap-filled-limited condition is the main mechanism of the charge trapping at higher voltage [27]. It further confirms the occurrence of charge trapping phenomenon across the 2D heterointerfaces between $\mathrm{TiO}_{2}$ and $\mathrm{Ga}_{2} \mathrm{O}_{3}$ $\left(\mathrm{N}_{2}-600{ }^{\circ} \mathrm{C}\right)$ films. The nonlinear variation of the current at higher voltage is fitted by the Child's law $\left(I \propto V^{2}\right)$. The charge trapping phenomena in $\mathrm{TiO}_{2}$ film and at the $\mathrm{TiO}_{2}-\mathrm{Ga}_{2} \mathrm{O}_{3}$ $\left(\mathrm{N}_{2}\right)$ heterointerfaces are expected to be the main mechanism for the resistive behavior at the middle range biased voltages. In the last stage of $I-V$ curve, which is called the trap-filled-limited region, an abrupt increase in current is observed when the voltage passes the threshold limit $\left(V_{\mathrm{TFL}}\right)$. By imposing higher voltage $(V>V \mathrm{TFL} \sim 0.9 \mathrm{~V})$, the device resistance changed from HRS to LRS. The above-mentioned observations confirmed the importance of the trap-controlled space-charge-limited current (SCLC) mechanism [28] in the resistive switching of heterostructured device. The graph of $\ln \left(1 / V^{2}\right)$ versus the $\ln (1 / V)$ has depicted the transition from the direct to the Fowler-Nordheim $(\mathrm{F}-\mathrm{N})$ tunneling [29] by gradual increase in the biased voltage. Graph showed that the specific inflection point was shifted to higher values after the first and second cyclic test (Fig. 5e). While two individual transport regimes were observed in the positive biased voltage, the device only experienced one transport regime corresponding to the negative biased voltages. It was also found that the band alignment of $\mathrm{TiO}_{2}-\mathrm{Ga}_{2} \mathrm{O}_{3}$ interface could be altered by RTA treatment of the $\mathrm{Ga}_{2} \mathrm{O}_{3}$ component (Figs. S11-S15 and Note S2). It was observed that the $\Delta E_{c}$ value of heterostructured film increased considerably at the $\mathrm{TiO}_{2}-\mathrm{Ga}_{2} \mathrm{O}_{3}\left(\mathrm{~N}_{2}-600{ }^{\circ} \mathrm{C}\right)$ heterointerfaces. It depicts the tangible difference between the conduction band energy levels of heterostructured component (Figs. $5 \mathrm{f}$ and S11). Therefore, it is expected that the heterointerface manipulation and the bandgap adjustment tangibly affected the charge transfer mechanisms in the $\mathrm{Ga}_{2} \mathrm{O}_{3}-\mathrm{TiO}_{2}$ heterointerfaces. Nitrogen as a strong acceptor can dope and diffuse into $\mathrm{Ga}_{2} \mathrm{O}_{3}$ film and alter the charge carrier mechanism [30]. Different memristive and rectification behavior of $\mathrm{TiO}_{2}-\mathrm{Ga}_{2} \mathrm{O}_{3}\left(\mathrm{~N}_{2}\right)$ devices can be related to different levels of $\mathrm{N}_{2}$ incorporation into $\mathrm{Ga}_{2} \mathrm{O}_{3}$ film at two annealing temperatures of 450 and $600{ }^{\circ} \mathrm{C}$ (XPS results in Fig. 4e). The Hall-effect measurements clearly demonstrated considerable decrease in the number of charge carriers at the $\mathrm{Ga}_{2} \mathrm{O}_{3}$ thin film annealed in $\mathrm{N}_{2}$ atmosphere. It confirms the compensation impact of the nitrogen acceptors on the oxygen-vacancy donors (Fig. S16).

A trapping-induced bipolar RS model is elaborated to explain the nonvolatile charge trapping mechanisms in the $\mathrm{Pt} / \mathrm{TiO}_{2}-\mathrm{Ga}_{2} \mathrm{O}_{3}\left(\mathrm{~N}_{2}\right) / \mathrm{Au}$ devices. It can be explained by considering the type of band alignment (type II) and the driving internal electric field caused by the potential difference between the $\mathrm{Ga}_{2} \mathrm{O}_{3}$ and $\mathrm{TiO}_{2}$ heterointerfaces components. Taking into account the bias polarity on $\mathrm{TiO}_{2}$ and $\mathrm{Ga}_{2} \mathrm{O}_{3}$ samples, the charge trapping/de-trapping process can happen either in semiconductor component or at the heterointerfaces. Considering the noble nature of $\mathrm{Au}$ and $\mathrm{Pt}$ electrodes, the electrochemical oxidation and reduction of electrodes are not expected to affect the resistive switching mechanisms. The trap level of oxygen vacancy in the $\mathrm{TiO}_{2}$ film was estimated to be $\sim 0.7 \mathrm{eV}$ below the conduction band edge [31], and the calculated Schottky barrier height at the $\mathrm{Pt} / \mathrm{TiO}_{2}$ films is $0.7 \mathrm{eV}$ (Note $\mathrm{S} 3$ and Fig. S17). Under the forward-biased voltage, the empty trap sites in the $\mathrm{TiO}_{2}$ film keep the device in HRS [32]. On the other hand, by applying efficient voltage on the Pt electrode, the energy level of the trap sites is pulled down until it reached the level below the Fermi energy of the Pt electrode. Consequently, the electrons could be injected into $\mathrm{TiO}_{2}$ layer either by direct tunneling or by $\mathrm{F}-\mathrm{N}$ tunneling through the $\mathrm{Pt}-\mathrm{TiO}_{2}$ Schlocky junction at higher biased voltage. The injected electrons then gradually fill the trapping sites (Fig. 6a). When the trapping sites are filled by electrons completely, the unique band alignment in the $\mathrm{TiO}_{2}-\mathrm{Ga}_{2} \mathrm{O}_{3}$ heterointerfaces can still suppress and trap the other injected electrons at the $\mathrm{TiO}_{2}-\mathrm{Ga}_{2} \mathrm{O}_{3}$ interface (Fig. 6a). As the biased voltage increased, the electrons pass the heterointerfaces barrier and flow through the ultra-thin RTA-treated $\mathrm{Ga}_{2} \mathrm{O}_{3}$ film. Here, the annealing process facilitated the charge transfer through the $\mathrm{Ga}_{2} \mathrm{O}_{3}$ layer since it can increase the amount of the metallic $\mathrm{Ga}$ excess in the $\mathrm{Ga}_{2} \mathrm{O}_{3}$ barrier layer and facilitate the HRS to LRS transition. By removing the forward-biased voltage, the band alignment 
(a)

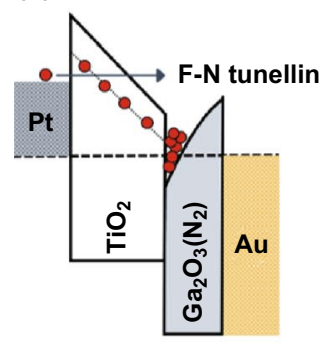

Forward bias

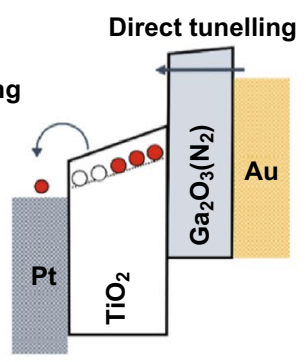

Reversed bias (b)

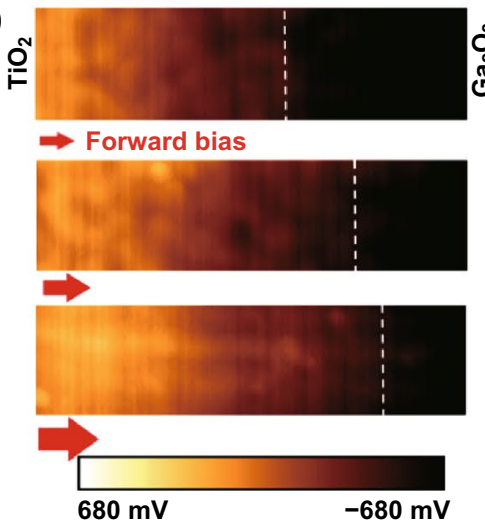

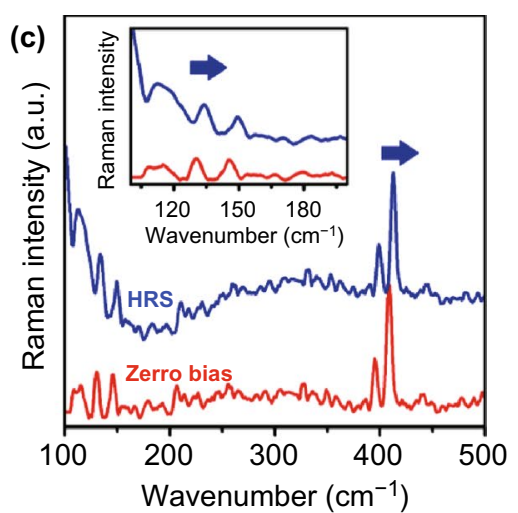

Fig. 6 a Schematic band diagram for charge transfer from $\mathrm{TiO}_{2}$ to $\mathrm{Ga}_{2} \mathrm{O}_{3}\left(\mathrm{~N}_{2}\right)$ devices. b KPFM analysis monitors the surface potential of memristor device between $\mathrm{Au}$ and $\mathrm{Pt}$ electrodes for a horizontally developed $\mathrm{TiO}_{2}-\mathrm{Ga}_{2} \mathrm{O}_{3}$ heterostructure. The scanning area was $1 \mu \mathrm{m}^{2}$. The bright area represents the electron trap regions, and the dark area depicts the hole trap regions. $\mathbf{c}$ Raman spectra of $\mathrm{TiO}_{2}$ film of memristor device in zero bias and HRS mode

in heterointerfaces returns to its initial condition. Thus, the instant de-trapping of charges occurs by imposing the reverse-biased voltage. Due to the internal electric field in the $\mathrm{TiO}_{2}-\mathrm{Ga}_{2} \mathrm{O}_{3}$, the traps stay longer and decaying process takes more time to be completed. The noisy characteristics of $I-V$ curves in Fig. $5 \mathrm{c}$ can be attributed to the charge detrapping [32]. These charges are expected to be trapped at higher energy levels compared with the Fermi level of the Pt electrode. The trapping-induced bipolar RS mechanism was previously observed in the heterostructured all-oxidebased resistive memories in neuromorphic devices [32-35]. Therefore, to monitor the potential across the heterointerfaces and to investigate migration of the oxygen vacancies, a specific horizontal configuration of the $\mathrm{TiO}_{2}-\mathrm{Ga}_{2} \mathrm{O}_{3}$ device is designed. This configuration of heterostructured oxide facilitates the overhead monitoring of samples by the Kelvin probe force microscopy (KPFM) (Fig. S18). To this aim, several snapshots of the surface potential of samples were monitored, while the forward potential was increasing (Fig. 6b). The brighter parts in the images are the manifestation of electron-trapped regions in which the surface potential is higher than that of the non-trapped parts [36]. The gradual increasing area of the bright region reinforces the proposed mechanism for the charge trapping and resistive switching at the heterointerfaces [37]. A uniform potential drop across the region between two heterointerfaces components was observed. It confirms the gradual filling of the trapping sites in the main oxide component of heterostructured film, i.e., $\mathrm{TiO}_{2}$ film. To further investigate the effect of oxygen vacancies on the resistance of memristor, the Raman measurements were carried out to monitor the $\mathrm{TiO}_{2}$ film at HRS and zero-bias conditions (Fig. 6c). The Raman characterization of heterointerfaces at the zero-biased state and at the HRS displayed the red shift of O1s and Ti-O Raman characteristic peaks after charge trapping phenomenon (Fig. 6c). It was observed that the occupation of trapping sites is accompanied by the decrease in concentration of the oxygen vacancies. This observation confirms the effect of oxygen-vacancy sites on the charge trapping mechanism.

\subsection{Nociceptor Devices}

The trapping/de-trapping characteristics of our all-oxideheterostructured nociceptor were accompanied by the internal electric field caused by the difference in electron affinity of $\mathrm{TiO}_{2}$ and $\mathrm{Ga}_{2} \mathrm{O}_{3}$ films. These observations bring the idea of the development of optically modulated resistive neuromorphic device. The fabricated samples are highly transparent $(\sim 80 \%)$ with the optical bandgap in the UV region (Fig. S19). This instrument is quite similar to the eye's cornea which is also highly transparent and has the highest number of nociceptors. Inset in Fig. 7a depicts a typical unit structure in which the transparent indium tin oxide (ITO) layer is deposited over $\mathrm{Au} / \mathrm{Ga}_{2} \mathrm{O}_{3}-\mathrm{TiO}_{2}$ heterostructure to make a conductive transparent electrode. Then, the device photoresponse was measured by imposing $0.1 \mathrm{~V}$ bias voltage under illumination of a tunable UV 

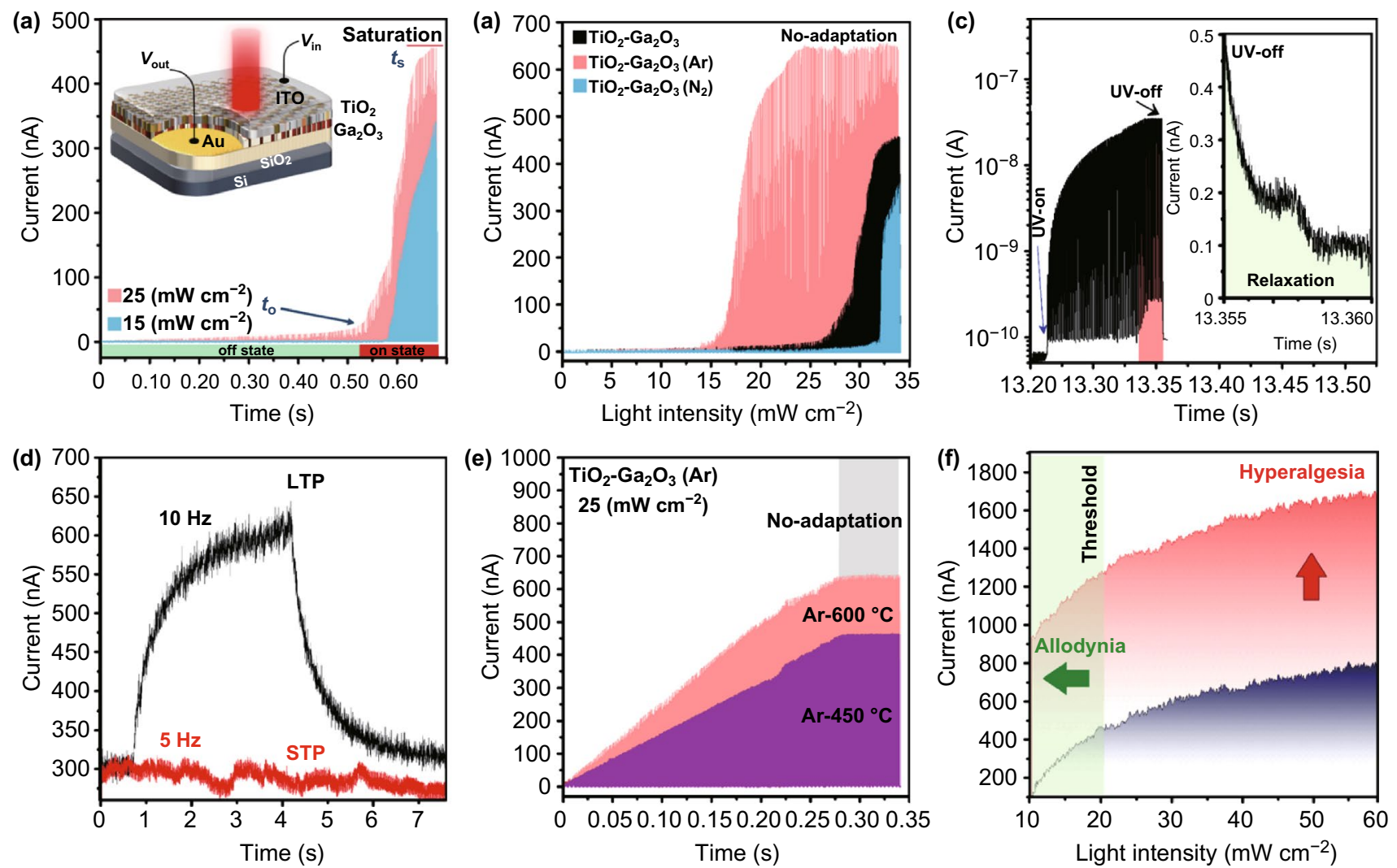

Fig. 7 The photoinduced nociceptive behavior of devices. a The light intensity-dependent photoresponse of $\mathrm{ITO}_{\mathrm{TiO}}-\mathrm{Ga}_{2} \mathrm{O}_{3} / \mathrm{Au}$ devices under $0.1 \mathrm{~V}$ bias showing the threshold and saturation characteristics. b Comparison of the typical photoresponse of various memristor devices showing the effect of heterointerface engineering on threshold and saturation characteristics of fabricated memristor devices. The ITO/TiO ${ }_{2}-\mathrm{Ga}_{2} \mathrm{O}_{3}$ $\left(\mathrm{N}_{2}-600{ }^{\circ} \mathrm{C}\right) / \mathrm{Au}$ nociceptive device shows the highest threshold values among various heterostructured devices. $\mathrm{c}$ Relaxation characteristics of ITO/TiO $-\mathrm{Ga}_{2} \mathrm{O}_{3}\left(\mathrm{~N}_{2}-600^{\circ} \mathrm{C}\right) / \mathrm{Au}$ nociceptive device under $35 \mathrm{~mW} \mathrm{~cm}{ }^{-2}$ pulsed laser $(360 \mathrm{~nm})$ illumination. $\mathbf{d}$ The effect of light frequency on relaxation time of nociceptor devices. e Allodynia characteristics of ITO/TiO ${ }_{2}-\mathrm{Ga}_{2} \mathrm{O}_{3}(\mathrm{Ar}) / \mathrm{Au}$ devices. f Allodynia and hyperalgesia of ITO/ $\mathrm{TiO}_{2}-\mathrm{Ga}_{2} \mathrm{O}_{3}(\mathrm{Ar}) / \mathrm{Au}$ devices

laser $(360 \mathrm{~nm})$. By increasing the light intensity to $25 \mathrm{~mW}$ $\mathrm{cm}^{-2}$ the photoresponse across the $\mathrm{Au} / \mathrm{Ga}_{2} \mathrm{O}_{3}-\mathrm{TiO}_{2} / \mathrm{ITO}$ device reached toward the saturation (Fig. 7a). This phenomenon is essential prerequisite parameters to satisfy the nociceptive characteristics of device. It was observed that the decrease in light intensity was accompanied by the delay of photoresponse initiation time and the delay of saturation time $\left(t_{\mathrm{s}}\right)$ of optical nociceptors (Fig. 7a). In ITO/TiO $-\mathrm{Ga}_{2} \mathrm{O}_{3}$ $\left(\right.$ Ar- $\left.600{ }^{\circ} \mathrm{C}\right) / \mathrm{Au}$ device, the photoresponse appeared and increased suddenly when the magnitude of light intensity was higher than $15 \mathrm{~mW} \mathrm{~cm} \mathrm{~cm}^{-2}$ (Fig. 7b). This observation indicates that the tangible photoinduced charge transport happens when enough photoinduced carriers are generated by the pulsed light. This is the basis of the threshold nature of fabricated optical nociceptor device. The magnified view of photocurrent response of nociceptor before and after the threshold is presented in Fig. S20. The distinguished nociceptor photoresponsivity in on- and off-states confirms that the threshold phenomenon has quite significant impact on nociceptive performance of fabricated devices. As an incredible observation, it was found that the required light intensity to turn on and then to get the saturation state in $\mathrm{TiO}_{2}-\mathrm{Ga}_{2} \mathrm{O}_{3}$ $\left(\mathrm{N}_{2}-600{ }^{\circ} \mathrm{C}\right)$ device is higher than that of $\mathrm{TiO}_{2}-\mathrm{Ga}_{2} \mathrm{O}_{3}$ and $\mathrm{TiO}_{2}-\mathrm{Ga}_{2} \mathrm{O}_{3}\left(\mathrm{Ar}-600{ }^{\circ} \mathrm{C}\right.$ ) devices (Fig. 7b). Furthermore, it was observed that the $t_{0}$ and $t_{\mathrm{s}}$ of $\mathrm{TiO}_{2}-\mathrm{Ga}_{2} \mathrm{O}_{3}$ unit are higher than those of $\mathrm{TiO}_{2}-\mathrm{Ga}_{2} \mathrm{O}_{3}\left(\mathrm{Ar}-600^{\circ} \mathrm{C}\right)$ device. It is observed that the turn-on time and saturation time of $\mathrm{TiO}_{2}-\mathrm{Ga}_{2} \mathrm{O}_{3}$ $\left(\mathrm{N}_{2}-600{ }^{\circ} \mathrm{C}\right)$ device are the highest value among all nociceptors. $\mathrm{TiO}_{2}$ is considered as the main charge generation and trapping component of all-oxide transparent heterostructure. Considering the similarity of $\mathrm{TiO}_{2}$ thickness in all devices, the $t_{0}$ and $t_{\mathrm{s}}$ values are mostly attributed to the 
charge transfer phenomenon in heterointerfaces. It was discovered that the $\Delta E_{\mathrm{c}}$ of $\mathrm{TiO}_{2}-\mathrm{Ga}_{2} \mathrm{O}_{3}\left(\mathrm{Ar}-600{ }^{\circ} \mathrm{C}\right)$ heterointerfaces is the smallest among all instruments, while the $\Delta E_{\mathrm{c}}$ of $\mathrm{TiO}_{2}-\mathrm{Ga}_{2} \mathrm{O}_{3}\left(\mathrm{~N}_{2}-600{ }^{\circ} \mathrm{C}\right)$ heterostructured film is the highest one. This higher barrier height in heterointerfaces can explain why it takes longer time and needs higher energy for $\mathrm{TiO}_{2}-\mathrm{Ga}_{2} \mathrm{O}_{3}\left(\mathrm{~N}_{2}\right)$ device to turn on and then to reach to the saturation state. These distinctions among our heterostructured devices enabled us to fabricate either high-sensitive $\mathrm{TiO}_{2}-\mathrm{Ga}_{2} \mathrm{O}_{3}$ (Ar) or high-threshold $\mathrm{TiO}_{2}-\mathrm{Ga}_{2} \mathrm{O}_{3}\left(\mathrm{~N}_{2}\right)$ nociceptors. It was found that after saturation, the device photocurrent does not change even by increasing the power density of the pulsed light (Fig. 7b). This behavior is similar to the no-adaptation characteristics of the natural human nociceptors, which protects the organs from the unnecessary and harmful external stimuli [38]. The signal relaxation is another important characteristic of the fabricated nociceptors. It explicitly refers to the required time for the ultimate decay of the response current after the elimination of light stimuli. Figure $7 \mathrm{c}$ depicts that the current increased suddenly and stayed constant for the rest of stimulation at $13.3 \mathrm{~s}$. Our observations confirmed that the relaxation time is dependent on the stimuli frequency where the increased light frequency has resulted in longer relaxation time (Fig. 7d). The device property is similar to the human nociceptors when a stronger pain is caused by intense and continuous stimuli and the pain lasts longer until it completely disappears. Furthermore, at higher frequencies the response signals overlap, resulting in the nociceptor charge accumulation (Fig. 7d). In this state, the remained generated photo-carriers of the previous spike facilitate the device conductance in the following stimulation stage. Similar behavior was observed in the synaptic units, which is called excitatory postsynaptic current (EPC). The EPC corresponds to the synaptic weight of a biological synapse which can be transferred from the short-term plasticity (STP) to the long-term potentiation (LTP) mode [39]. This characteristic is also similar to the human nociceptors when even a weak hazardous stimulus triggers a strong chronic pain.

Figure $7 \mathrm{e}$ shows the photoresponsivity of ITO/ $\mathrm{TiO}_{2}-\mathrm{Ga}_{2} \mathrm{O}_{3}(\mathrm{Ar}) / \mathrm{Au}$ units where allodynia characteristic is observed in the damaged states. As it is depicted, at the constant light intensity of $25 \mathrm{~mW} \mathrm{~cm}^{-2}$ the threshold times $\left(t_{\mathrm{o}}\right)$ have shifted to the initial illumination stage. It was demonstrated the RTA samples $\left(\operatorname{Ar}-600{ }^{\circ} \mathrm{C}\right)$ provided higher photoresponsivity. The nociceptor behaved similar to a receptor at this state. However, since the light intensity is constant $\left(25 \mathrm{~mW} \mathrm{~cm}^{-2}\right)$, the no-adaptation state is still observed. Interestingly, the $\mathrm{TiO}_{2}-\mathrm{Ga}_{2} \mathrm{O}_{3}\left(\mathrm{~N}_{2}\right)$ devices do not show the allodynia at the same light stimulation (Fig. S21), which vividly depicts the heterointerfaces manipulation effect on nociceptive behavior. In addition, when the light intensity is increased, the hyperalgesia phenomenon is also detected in $\mathrm{TiO}_{2}-\mathrm{Ga}_{2} \mathrm{O}_{3}(\mathrm{Ar}$ ) nociceptors (Fig. 7f). The long-term stability of nociceptors was confirmed after conducting several tests on other devices with the same configuration and preparation steps. Figure S22 demonstrates the cyclic $I-V$ curves of ITO/TiO $-\mathrm{Ga}_{2} \mathrm{O}_{3}\left(\mathrm{~N}_{2}\right) / \mathrm{Au}$ device at several cyclic sequences and under the illumination of light source with different intensities. The memristive behavior of heterostructured semiconductor device under light illumination was different compared with the performance of device in darkness. The combined effects of increased light intensity and higher cyclic number made the device to face its photocurrent threshold where the no-adaptation state occured. The photogenerated electron and holes evidently affected the trapping and transfer of charge carriers in all-oxide heterostructured device, as it was reported previously in the study of resistive behavior of heterostructured oxide semiconductor devices [40]. On the basis of experimental observations, a plausible model has been introduced to explain the operating mechanism of our optoelectronic nociceptor (Fig. S23). The tangible difference between the electron affinity of $\mathrm{TiO}_{2}$ and $\mathrm{Ga}_{2} \mathrm{O}_{3}$ accompanied by the imposed biased voltage facilitates the transfer of the photogenerated charges from $\mathrm{TiO}_{2}$ to $\mathrm{Ga}_{2} \mathrm{O}_{3}$. The type-II heterointerfaces cause charge trapping at the positive biased voltage. Because of the interfacial barrier height, the electrons mostly transport from $\mathrm{TiO}_{2}$ to $\mathrm{Ga}_{2} \mathrm{O}_{3}$ film by $\mathrm{F}-\mathrm{N}$ tunneling mechanism [41]. The developed heterointerfaces can act as the rapping site for generated electrons and holes after removing the light stimuli source. The $\mathrm{N}_{2}$-doped $\mathrm{Ga}_{2} \mathrm{O}_{3}$ acts as the hole acceptor component of heterostructure. Under the impact of the applied electric field, the generated holes drift toward the $\mathrm{N}_{2}$-doped $\mathrm{Ga}_{2} \mathrm{O}_{3}$. If the light stimulus is strong enough, the generated charge carriers remain highly stable at the heterointerfaces and increase the relaxation time. 


\section{Conclusions}

All-oxide-heterostructured optoresponsive nociceptor with controllable charge transfer is fabricated. Newly designed nociceptor utilized ultra-thin sub-stoichiometric amorphous $\mathrm{TiO}_{2}-\mathrm{Ga}_{2} \mathrm{O}_{3}$ heterostructures. Ultra-thin $\mathrm{Ga}_{2} \mathrm{O}_{3}$ films were thermally annealed in $\mathrm{Ar}$ and $\mathrm{N}_{2}$ atmospheres. It was discovered that the phase reconfiguration in $\mathrm{Ga}_{2} \mathrm{O}_{3}$ was accompanied by the substantial jump in its conductivity induced by the thermally assisted redox reaction of amorphous nanostructure in Ar atmosphere. The artificial nociceptor has clearly demonstrated the threshold, relaxation, allodynia, and hyperalgesia states closely resembling the human bio-nociceptor behavior. The artificial nociceptor functions are based on unique switching behavior and outstanding dynamics of memristor. It was experimentally confirmed that the charge transfer can be tuned and controlled by the interfaces manipulation in the ultra-thin heterostructures. The heterointerface manipulation ultimately enabled fabrication of either high-sensitive $\mathrm{TiO}_{2}-\mathrm{Ga}_{2} \mathrm{O}_{3}$ (Ar) nociceptor or the high-threshold $\mathrm{TiO}_{2}-\mathrm{Ga}_{2} \mathrm{O}_{3}\left(\mathrm{~N}_{2}\right)$ nociceptor. The newly designed optoresponsive nociceptor can be readily readjusted to be responsive to other stimuli such as chemicals. Such versatility can have profound impact on wide range of applications where the human presence is considered as extremely hazardous. Moreover, due to its bio-realistic capabilities and scalability advantage over the existing microstructured counterparts, developed nociceptors are highly desirable to be utilized in micro- and nano-robotics at various environmental conditions.

Acknowledgements The work was supported by Research and Development Program of the Ghent University Global Campus, South Korea.

Open Access This article is licensed under a Creative Commons Attribution 4.0 International License, which permits use, sharing, adaptation, distribution and reproduction in any medium or format, as long as you give appropriate credit to the original author(s) and the source, provide a link to the Creative Commons licence, and indicate if changes were made. The images or other third party material in this article are included in the article's Creative Commons licence, unless indicated otherwise in a credit line to the material. If material is not included in the article's Creative Commons licence and your intended use is not permitted by statutory regulation or exceeds the permitted use, you will need to obtain permission directly from the copyright holder. To view a copy of this licence, visit http://creativecommons.org/licenses/by/4.0/.
Electronic supplementary material The online version of this article (https://doi.org/10.1007/s40820-020-00419-z) contains supplementary material, which is available to authorized users.

\section{References}

1. M. Karbalaei Akbari, S. Zhuiykov, A bioinspired optoelectronically engineered artificial neurorobotics device with sensorimotor functionalities. Nat. Commun. 10, 3873 (2019). https://doi.org/10.1038/s41467-019-11823-4

2. Y. Van de Burgt, A. Melianas, S.T. Keene, G. Malliaras, A. Salleo, Organic electronics for neuromorphic computing. Nat. Electron. 1, 386-397 (2018). https://doi.org/10.1038/ s41928-018-0103-3

3. C.D. Gilbert, W. Li, Top-down influences on visual processing. Nat. Rev. Neurosci. 14, 350-363 (2013). https://doi. org/10.1038/nrn3476

4. D. Holmes, The pain drain. Nature 535, S2-S3 (2016). https ://doi.org/10.1038/535S2a

5. D. Holmes, Reconstructing the retina. Nature 561, S2-S3 (2018). https://doi.org/10.1038/d41586-018-06111-y

6. J.H. Yoon, Z. Wang, K.M. Kim, H. Wu, V. Ravichandran, Q. Xia, C.S. Hwang, J.J. Yang, An artificial nociceptor based on a diffusive memristor. Nat. Commun. 9, 417 (2018). https ://doi.org/10.1038/s41467-017-02572-3

7. M. Kumar, H.S. Kim, J.A. Kim, A highly transparent artificial optical nociceptor. Adv. Mater. 31, 1900021 (2019). https://doi.org/10.1002/adma.201900021

8. M.S. Gold, G.F. Gebhart, Nociceptor sensitization in pain pathogenesis. Nat. Med. 16, 1248-1257 (2010). https://doi. org/10.1038/nm.2235

9. Y. Kim, Y.J. Kwon, E.K. Dae, Nociceptive memristor. Adv. Mater. 30, 1704320 (2018). https://doi.org/10.1002/ adma.201704320

10. L. Nagarajan, R.A. De Souza, D. Samuelis, I. Valov, A. Börger et al., A chemically driven insulator-metal transition in non-stoichiometric and amorphous gallium oxide. Nat. Mater. 7, 391-398 (2008). https://doi.org/10.1038/nmat2164

11. C. Kranert, C. Sturm, R. Schmidt-Grund, M. Grundmann, Raman tensor elements of $\beta-\mathrm{Ga}_{2} \mathrm{O}_{3}$. Sci. Rep. 6, 35964 (2016). https://doi.org/10.1038/srep35964

12. Z.Y. Al Balushi, K. Wang, R.K. Ghosh, R.A. Vilá, S.M. Eichfeld et al., Two dimensional gallium nitride realized via graphene encapsulation. Nat. Mater. 15, 1166-1171 (2016). https://doi.org/10.1038/nmat4742

13. J. Kim, T. Sekiya, N. Miyokawa, Conversion of an ultra-wide bandgap amorphous oxide insulator to a semiconductor. NPG Asia Mater. 9, e359 (2017). https://doi.org/10.1038/ am.2017.20

14. M. Martin, R. Dronskowski, J. Janek, K.-D. Becker, D. Roehrens et al., Thermodynamic, structure and kinetic in the system Ga-O-N. Prog. Solid State Chem. 37, 
132-152 (2009). https://doi.org/10.1016/j.progsolidstchem .2009 .11 .005

15. M. Karbalaei Akbari, Z. Hai, Z. Wei, R.K. Ramachandran, C. Detavernier et al., Sonochemical functionalization of the low dimensional surface oxide of Galinstan for heterostructured optoelectronic applications. J. Mater. Chem. C 7, 5584-5595 (2019). https://doi.org/10.1039/c9tc01079c

16. T.S. Ngo, D.D. Le, J.-H. Song, S.-K. Hong, Growth and characterization of gallium oxide films grown with nitrogen by plasma-assisted molecular-beam epitaxy. Thin Solid Films 682, 93-98 (2019). https://doi.org/10.1016/j.tsf.2019.05.029

17. Y. Zhang, J. Yan, Q. Li, C. Qu, L. Zhang, T. Li, Structural and optical properties of $\mathrm{N}$-doped $\mathrm{B}-\mathrm{Ga}_{2} \mathrm{O}_{3}$ films deposited by RF magnetron sputtering. Phys. B 406, 3079-3082 (2011). https://doi.org/10.1016/j.physb.2011.05.011

18. D. Song, L. Li, B. Li, A. Shen, Band gap engineering of $\mathrm{N}$-alloyed $\mathrm{Ga}_{2} \mathrm{O}_{3}$ thin films. AIP Adv. 6, 065016 (2016). https ://doi.org/10.1063/1.4954720

19. J.P. Perdew, J.A. Chevary, S.H. Vosko, Atoms, molecules, solids, and surfaces: applications of the generalized gradient approximation for exchange and correlation. Phys. Rev. B 48, 4978 (1993). https://doi.org/10.1103/PhysRevB.46.6671

20. Y.P. Song, H.Z. Zhang, C. Lin, Y.W. Zhu, G.H. Li, F.H. Yang, D.P. Yu, Luminescence emission originating from nitrogen doping of $\beta-\mathrm{Ga}_{2} \mathrm{O}_{3}$ nanowires. Phys. Rev. B 69, 075304 (2004). https://doi.org/10.1103/PhysRevB.69.075304

21. T.C. Chang, K.C. Chang, T.M. Tsai, Resistive random access memory. Mater. Today 19, 254-264 (2016). https://doi. org/10.1016/j.mattod.2015.11.009

22. K.M. Kim, J. Zhang, C. Graves, J.J. Yang, B.J. Choi, C.S. Hwang, Z. Li, R.S. Williams, Low-power, self-rectifying, and forming-free memristor with an asymmetric programing voltage for a high-density crossbar application. Nano Lett. 16, 6724-6732 (2016). https://doi.org/10.1021/acs.nanolett.6b017 81

23. D.H. Kwon, K.M. Kim, J.H. Jang, J.M. Jeon, M.H. Lee et al., Atomic structure of conducting nanofilaments in $\mathrm{TiO}_{2}$ resistive switching memory. Nat. Nanotechnol. 5, 148-153 (2010). https://doi.org/10.1038/nnano.2009.456

24. D. Lee, J.W. Park, N.K. Cho, J. Lee, Y.S. Kim, Verification of charge transfer in metal-insulator-oxide semiconductor diodes via defect engineering of insulator. Sci. Rep. 9, 10323 (2019). https://doi.org/10.1038/s41598-019-46752-1

25. M. Kumar, S. Abbas, J. Kim, All oxide highly transparent synapse for neuromorphic computing. ACS Appl. Mater. Interface 10, 34370-34376 (2018). https://doi.org/10.1021/acsam i. 8 b 10870

26. S. Choi, S. Jang, J.H. Moon, J.C. Kim, H.Y. Jeong, P. Jang, K.J. Lee, G. Wang, A self-rectifying $\mathrm{TaO}_{\mathrm{y}} /$ nanoporous $\mathrm{TaO}_{\mathrm{x}}$ memristor synaptic array for learning and energy-efficient neuromorphic systems. NPG Asia Mater. 10, 1097-1106 (2018). https://doi.org/10.1038/s41427-018-0101-y
27. M. Kumar, S.K. Hazra, T. Som, Role of metallic like conductivity in unusual temperature-dependent transport in n-ZnO: Al/p-Si heterojunction diode. J. Phys. D-Appl. Phys. 48, 455301 (2015). https://doi.org/10.1088/00223727/48/45/455301

28. S.R. Zhang, L. Zhou, J.Y. Mao, Y. Ren, J.Q. Yang et al., Artificial synapse emulated by charge trapping-based resistive switching device. Adv. Mater. Technol. 4, 1800342 (2019). https://doi.org/10.1002/admt.201800342

29. F.P.G. Arquer, X. Gong, R.P. Sabatini, M. Liu, G.H. Kim et al., Field-emission from quantum-dot-in-perovskite solids. Nat. Commun. 8, 14757 (2017). https://doi.org/10.1038/ncomm s14757

30. E. Chikoidze, C. Sartel, H. Mohamed, I. Madaci, T. Tchelidze et al., Enhancing the intrinsic p-type conductivity of the ultrawide bandgap $\mathrm{Ga}_{2} \mathrm{O}_{3}$ semiconductor. J. Mater. Chem. C 7, 10231-10239 (2019). https://doi.org/10.1039/C9TC02910A

31. D. Valentin, G. Pacchoni, Reduced and n-type doped $\mathrm{TiO}_{2}$ : nature of $\mathrm{Ti}^{3+}$ species. J. Phys. Chem. C 113, 20543-20552 (2009). https://doi.org/10.1021/jp9061797

32. J.H. Yoon, S.J. Song, I.H. Yoo, J.Y. Seok, K.J. Yoon, D.E. Kwon, T.H. Park, C.S. Hwang, Highly uniform, electroforming-free, and self-rectifying resistive memory in the $\mathrm{Pt} / \mathrm{Ta}_{2} \mathrm{O}_{5} /$ $\mathrm{HfO}_{2-\mathrm{x}} / \mathrm{TiN}$ Structure. Adv. Funct. Mater. 24, 5086 (2014). https://doi.org/10.1002/adfm.201400064

33. J.H. Yoon, K.M. Kim, S.J. Song, J.Y. Seok, K.J. Yoon et al., $\mathrm{Pt} / \mathrm{Ta}_{2} \mathrm{O}_{5} / \mathrm{HfO}_{2-} \mathrm{x} / \mathrm{Ti}$ resistive switching memory competing with multilevel NAND flash. Adv. Mater. 27, 3811 (2015). https://doi.org/10.1002/adma.201501167

34. S. Kumar, N. Davila, Z. Wang, X. Huang, J.P. Strachan et al., Spatially uniform resistance switching of low current, high endurance titanium-niobium-oxide memristors. Nanoscale 9, 1793-1798 (2017). https://doi.org/10.1039/C6NR07671H

35. A. Wedig, M. Luebben, D.Y. Cho, M. Moors, K. Skaja et al., Nanoscale cation motion in $\mathrm{TaO}_{\mathrm{x}}, \mathrm{HfO}_{\mathrm{x}}$ and $\mathrm{TiO}_{\mathrm{x}}$ memristive systems. Nat. Nanotechnol. 11, 67-74 (2016). https://doi. org/10.1038/NNANO.2015.221

36. Y. Wang, Z. Lv, J. Chen, Z. Wang, Y. Zhou, L. Zhou, X. Chen, S.T. Han, Photonic synapses based on inorganic perovskite quantum dots for neuromorphic computing. Adv. Mater. 30, 1802883 (2018). https://doi.org/10.1002/adma.201802883

37. X. Zhu, D. Li, X. Liang, W.D. Lu, Ionic modulation and ionic coupling effects in $\mathrm{MoS}_{2}$ devices for neuromorphic computing. Nat. Mater. 18, 141-148 (2019). https://doi.org/10.1038/s4156 3-018-0248-5

38. J. Sandkühler, Models and mechanisms of hyperalgesia and allodynia. Physiol. Rev. 89, 707-758 (2009). https://doi. org/10.1152/physrev.00025.2008

39. Y. Burgt, E. Lubberman, E.J. Fuller, S.T. Keene, G.C. Faria et al., A non-volatile organic electrochemical device as a lowvoltage artificial synapse for neuromorphic computing. Nat. Mater. 16, 414-418 (2017). https://doi.org/10.1038/nmat4856 
40. P. Zheng, B. Sun, Y. Chen, H. Elshekh, T. Yu et al., Photoinduced negative differential resistance in a resistive switching memory device based on $\mathrm{BiFeO}_{3} / \mathrm{ZnO}$ heterojunctions. Appl. Mater. Today 14, 21-28 (2019). https://doi.org/10.1016/j. apmt.2018.11.007
41. S. Pandey, C. Biswas, T. Ghosh, Transition from direct to Fowler-Nordheim tunnelling in chemically reduced graphene oxide film. Nanoscale 6, 3410-3417 (2014). https:// doi.org/10.1039/C3NR05675A 